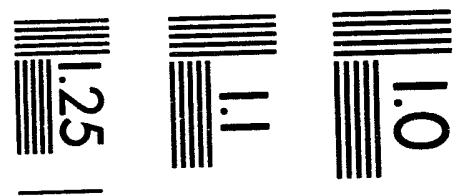

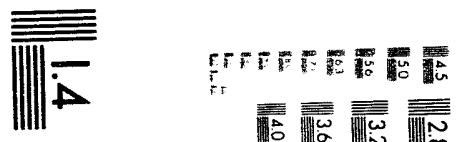

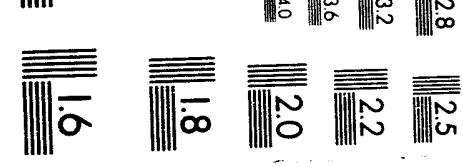



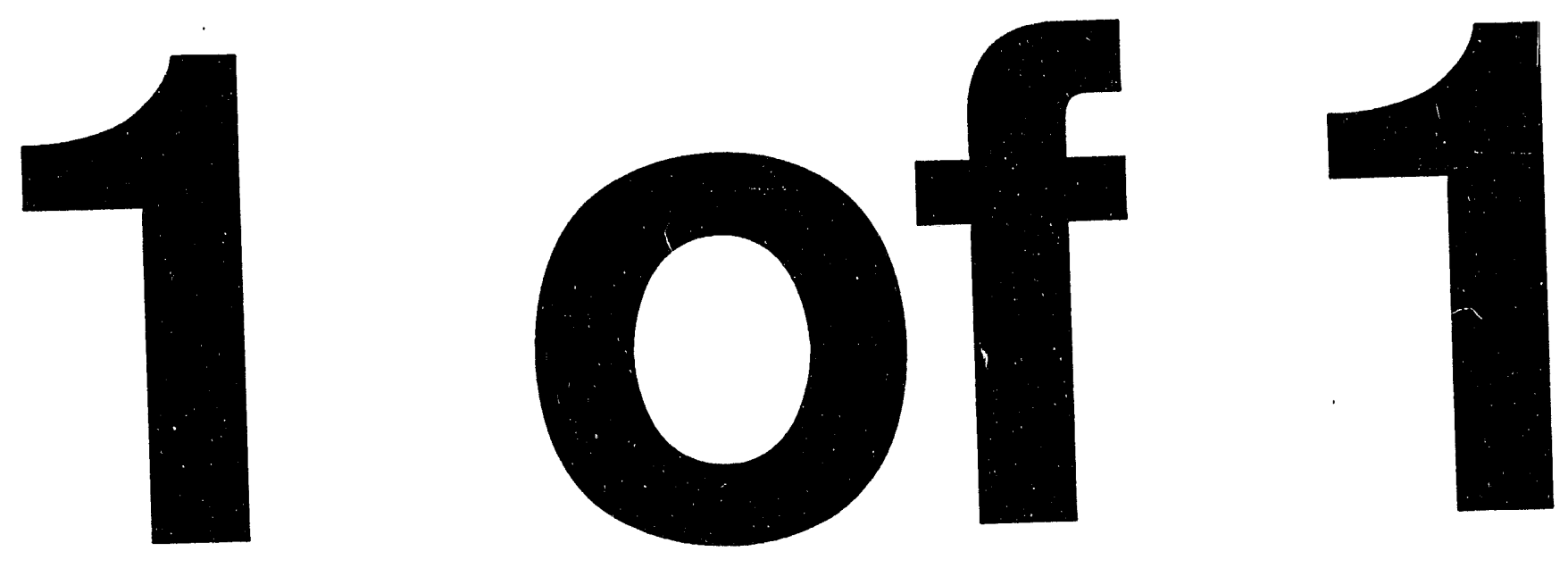


\section{EVALUATION AND SELECTION OF AQUEOUS-BASED TECHNOLOGY FOR PARTITIONING RADIONUCLDES FROM ICPP CALCINE}
A. L Otson (WINCO)
W. W. Schulz
L A. Burchfield
C. D. Cartson
J. L Swanson
M. C. Thompson

February 1993

\section{Westinghouse Idaho}

PREPARED FOR THE

DEPARTMENT OF ENERGY

IDAHO OPERATIONS OFFICE

UNDER CONTRACT DE-AC07-84ID12435

\section{MASTER}




\section{EXECUTIVE SUMMARY}

Early in 1993 Westinghouse Idaho Nuclear Company (WINCO) chartered a Panel of Nuclear Separations Experts. The purpose of this Panel was to assist WINCO scientists and engineers in selecting, evaluating, and ranking candidate aqueous-based processes and technologies for potential use in partitioning selected radionuclides from nitric acid solutions of retrieved Idaho Chemical Processing Plant (ICPP) calcine. Radionuclides of interest are all transuranium elements, ${ }^{90} \mathrm{Sr},{ }^{99} \mathrm{Tc},{ }^{129} \mathrm{I}$, and ${ }^{137} \mathrm{Cs}$. The six man Panel, consisting of US Department of Energy contractor employees and outside consultants, met with involved WINCO technical and management personnel for 4 days (February 16-19, 1993) on the campus of the Idaho State University in Pocatello, Idaho. Principal topics addressed included:

- Available radionuclide removal technology

- Applicability of separations technology and processes to ICPP calcine - Potential integrated radionuclide partitioning schemes

This report, prepared from contributions from all Panel members, presents a comprehensive account of the proceedings and significant findings of the February, 1993 meeting in Pocatello. 


\section{TABLE OF CONTENTS}

1.0 INTRODUCTION . . . . . . 1-1

1.1 ROLE OF THE IDAHO CHEMICAL PROCESSING PLANT ....... 1-1

1.2 FINAL DISPOSAL OF ICPP CALCINE-ALTERNATIVE APPROACHES ..... 1-3

1.3 DEFINITION AND SELECTION OF RADIONUCLIDE PARTITIONING

TECHNOLOGY .................... 1-4

2.0 ASSUMPTIONS AND BASES ........................ 2-

3.0 DESCRIPTION OF APPLICABLE SEPARATIONS TECHNOLOGY . . . . . . 3-1

3.1 INTRODUCTION . . . . . . . . . . . . . . . .

3.2 LIQUID-LIQUID EXTRACTION PROCESSES ........... . 3-1

3.2.1 Transuranium Elements ............ 3-1

3.2.2 Cesium and Strontium ............. 3-. 3

3.2.3 Technetium . . . . . . . . . . . 3-5

3.2.4 Iodine . . . . . . . . . . . . . . 3-6

3.3 ION EXCHANGE TECHNOLOGY ................ . . . . . . . .

3.3.1 Transuranium Elements . . . . . . . . . . . 3-6

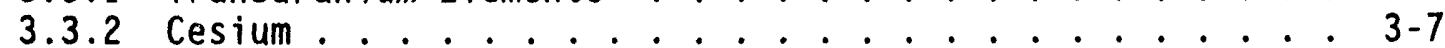

3.3.3 Strontium . . . . . . . . . . . . . . 3-9

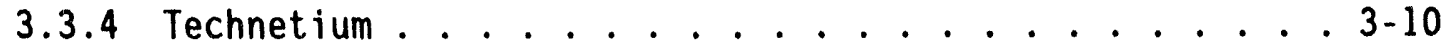

3.4 EXTRACTION CHROMATOGRAPHIC TECHNOLOGY ......... 3-10

3.4 .1 Introduction .................. 3-10

3.4.2 Transuranium Elements . . . . . . . . . 3-10

3.4.3 Strontium ................ 3-11

3.4 .4 Cesium ................ . . . . . . . . .

3.4 .5 Technetium . . . . . . . . . . . . . . 3-13

3.4 .6 Iodine . . . . . . . . . . . 3-13

3.5 PRECIPITATION - COPRECIPITATION TECHNOLOGY . . . . . . 3-13

3.5.1 Introduction . . . . . . . . . . . . . 3-13

3.5.2 TRU Elements ................ . . 3-14

3.5 .3 Strontium ................. 3-15

3.5 .4 Cesium ................. . . 3-15

3.5 .5 Technetium . . . . . . . . . . . . 3-17

3.5 .6 Iodine .................. 3-17

4.0 APPLICATION OF SEPARATIONS TECHNOLOGY TO ICPP CALCINE ...... 4 - 1

4.1 INTRODUCTION .................. . . . . . .

4.2 CHARACTERIZATION OF ICPP CALCINE ............ 4 . . .

4.3 DISSOLUTION OF ICPP CALCINE . . . . . . . . . . . 4-2

4.3.1 Water Leaching. . . . . . . . . . . . . . . 4-2

4.3.2 Acid Dissolution . . . . . . . . . . . . . 4-2

4.3.3 Systematic Calcine Leach/Dissolution Studies..... 4-2

4.4 STABILITY OF ACIDIC CALCINE DISSOLVER SOLUTIONS ....... . 4-3

4.5 EVALUATION AND RANKING OF CANDIDATE SEPARATIONS PROCESSES AND

TECHNOLOGY .................... 4-4

4.5.1 Introduction . . . . . . . . . . . 4-4

4.5.2 Transuranium Elements ............ 4-5

4.5 .3 Strontium .............. 4-. 4

4.5.4 Technetium . . . . . . . . . . . . . . . 4-9

4.5 .5 Cesium . . . . . . . . . . . . . . . 4-9

4.5 .6 Iodine ................ 4-13 
5.0 POTENTIAL INTEGRATED RADIONUCLIDE PARTITIONING SCHEMES . . . . . 5-1

5.1 INTRODUCTION . . . . . . . . . . . . . . . . . . 5-1

5.2 CONCEPTUAL PROCESSING SCHEMES ........... 5-2

5.2.1 Scheme 1 (Figure 5-2.) . . . . . . . . . . 5-2

5.2 .2 Scheme 2 (Figure $5-3$ ) ........... 5-5

5.2.3 Scheme 3 (Figure 5-4) . . . . . . . . . . 5-5

5.2 .4 Scheme 4 (Figure 5-5) ........... 5-8

5.2 .5 Scheme 5 (Figure 5-6) .......... 5-8

6.0 LABORATORY TESTING RECOMMENDATIONS . . . . . . . . . . 6-1

6.1 INTRODUCTION . . . . . . . . . . . . . . . . 6-1

6.2 LITERATURE AND OTHER RESOURCES ............. . . 6-1

6.3 CHARACTERIZATION OF PROCESS REAGENTS .......... . 6-1

6.4 SOLVENT EXTRACTION TEST PROCEDURES . . . . . . . . 6-3

6.5 ION EXCHNAGE/EXTRACTION CHROMATOGRAPHIC TEST PROCEDURES . . . . $6-5$

6.6 PRECIPITATION/COPRECIPITATION PROCESS TEST PROCEDURES . . . . $6-7$

7.0 REFERENCES ....................... . . . . . . .

APPENDIX A. SELECTED DATA CONCERNING SOURCE, COMPOSITION AND PROPERTIES OF ICPP CALCINE . . . . . . . . . . . . . 7-3

APPENDIX B. BIOGRAPHICAL INFORMATION FOR SEPARATIONS EXPERTS PANEL . . 7-4

FIGURES

Figure 1-1. Source of High-Level Waste from Reprocessing of Fuel at the ICPP .............. . . 1-2

Figure 5-1. Calcine Dissolution and Iodine Removal ......... . 5-3

Figure 5-2. Radionuclide Removal in Separated Processes ....... 5-4

Figure 5-3. Some Promising ${ }^{137} \mathrm{Cs}$ Removal Processes . . . . . . . . . 5-6

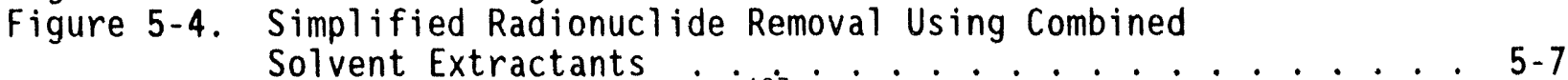

Figure 5-5. Application of Advanced ${ }^{137}$ Cs Removal Technology ..... 5-9

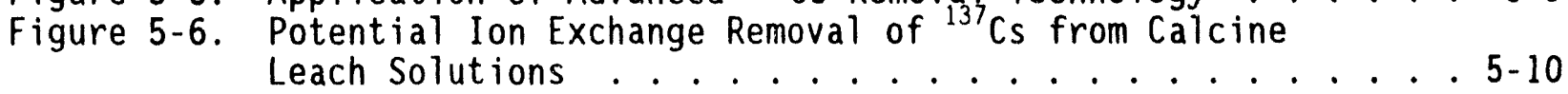

\section{TABLES}

TABLE 4.1 Candidate Tru Element Removal Technologies . . . . . . . . . 4-6

TABLE 4.2 Ranking of Candidate Tru Element Separations

Technologies ............. . . . 4-6

TABLE 4.3 Candidate Strontium Removal Technologies . . . . . . . . . 4-8

TABLE 4.4 Ranking of Candidate Strontium Separation Technologies . . . 4-8

TABLE 4-5 Candidate Technetium Removal Technologies ...... . . . . 4-10

TABLE 4-6 Ranking of Candidate Technetium Removal Technologies . . . . . 4-10

TABLE 4-7 Candidate Technologies for Removal of Cesium . . . . . . . . . 4-11

TABLE 4-8 Ranking of Candidate Cesium Removal Technologies . . . . . . . 4-12

TABLE 4-9 Candidate Iodine Removal Technologies . . . . . . . . . 4-14

TABLE 4-10 Ranking of Candidate Iodine Removal Technologies . . . . . . 4-14 


\section{LIST OF ACRONYMS}

$\begin{array}{ll}\text { CMPO } & \text { Octyl (phenyl)-N,N-diisobutylcarbamoylmethyl } \\ \text { CST } & \text { phosphine oxide } \\ \text { DBBP } & \text { Crystalline Silicotitanate } \\ \text { DHDECMP } & \text { Dibutylbutylphosphonate } \\ \text { DIDPA } & \text { Dihexyl-N,N-diethylcarbamoyimethylphosphonate } \\ \text { DOE } & \text { Diisodecylphosphoric Acid } \\ \text { EC } & \text { Department of Energy } \\ \text { GTM } & \text { Extraction Chromatography } \\ \text { HAN } & \text { Generic TRUEX Model } \\ \text { HDEHP } & \text { Hydroxylamine Nitrate } \\ \text { HPT } & \text { Bis(2-ethylhexyl)phosphoric Acid } \\ \text { ICPP } & \text { Hydrogenated Propylene Tetramer } \\ \text { IX } & \text { Idaho Chemical Processing Plant } \\ \text { IX } & \text { Ion Exchange-Inorganic Materials } \\ \text { NPH } & \text { Ion Exchange-Organic Materials } \\ \text { PPT } & \text { Normal Paraffin Hydrocarbons } \\ \text { PTA } & \text { Precipitation and/or Coprecipitation } \\ \text { SREX } & \text { Phosphotungstic ACid } \\ \text { Sr.Spec } & \text { Strontium Extraction } \\ \text { SX } & \text { Strontium Specific EC Material } \\ \text { TBP } & \text { Solvent Extraction } \\ \text { TPB } & \text { Tributyl Phosphate } \\ \text { TRU } & \text { Tetraphenylboron } \\ \text { TRUEX } & \text { Transuranium } \\ \text { TRU.Spec } & \text { Transuranium Extraction } \\ \text { VOL } & \text { Transuranium Specific EC Material } \\ \text { WINCO } & \text { Volatilization } \\ & \text { Westinghouse Idaho Nuclear Company }\end{array}$




\subsection{INTRODUCTION}

\subsection{ROLE OF THE IDAHO CHEMICAL PROCESSING PLANT}

The Idaho Chemical Processing PIant (ICPP) is located at the U.S. Department of Energy (DOE) Idaho National Engineering Laboratory in Idaho. For almost two score years (1953-1992) the ICPP reprocessed certain irradiated government nuclear fuel to recover ${ }^{235} U$ values. Fuels reprocessed in the ICPP were fabricated from three principal materials: aluminum (Wheeler et al. 1966); Zircaloy (Henry et al. 1973); stainless steel (Dukas et al. 1986). A special campaign was also conducted to recover ${ }^{235} \mathrm{U}$ from irradiated Rover Reactor fuel (Hogg et al. 1973).

Fuels to be reprocessed in the ICPP were completely dissolved in either $\mathrm{HNO}_{3}, \mathrm{HNO}_{3}-\mathrm{HF}$, or $\mathrm{H}_{2} \mathrm{SO}_{4}$ solutions. Subsequently, ${ }^{235} \mathrm{U}$ was separated and decontaminated by a liquid-liquid extraction process which employed one tributyl phosphate extraction cycle and two methylisobutyl ketone extraction cycles (Figure 1.1). Fission products, transuranium (TRU) elements, and inert feed components, e.g., zirconium, aluminum, fluoride ions, etc., all reported to the high-level aqueous waste stream.

All of the ICPP high-level waste was initially stored as an acidic solution in stainless steel tanks. Except for a small amount of waste still stored in liquid form in steel tanks, the high-level waste was solidified by thermal treatment at $500{ }^{\circ} \mathrm{C}$ in a fluidized-bed calciner (Figure 1.1) (Berreth and Dickey 1982). As noted in Figure 1.1, calcium was added to the high-level waste prior to calcination to inhibit fluoride volatility and thereby minimize corrosion of the calciner equipment. Approximately $3,500 \mathrm{~m}^{3}$ of calcined waste are presently stored in five stainless steel bins placed within concrete vaults emplaced in near-surface locations at the Idaho site. The calcine is judged to be retrievable for the design life (500 y) of the calcine storage vaults (WASH-1202 1972). The stainless steel storage bins are about $4 \mathrm{~m}$ in diameter and range from 12.5 to $18.5 \mathrm{~m}$ high.

Berreth (1988) notes that the calcine is a mixture of "bed" particles ranging between 0.2 to $0.5 \mathrm{~mm}$ diameter and of "fines" which are mostly between 
Source of Chemicals in ICPP

High Level Wastes

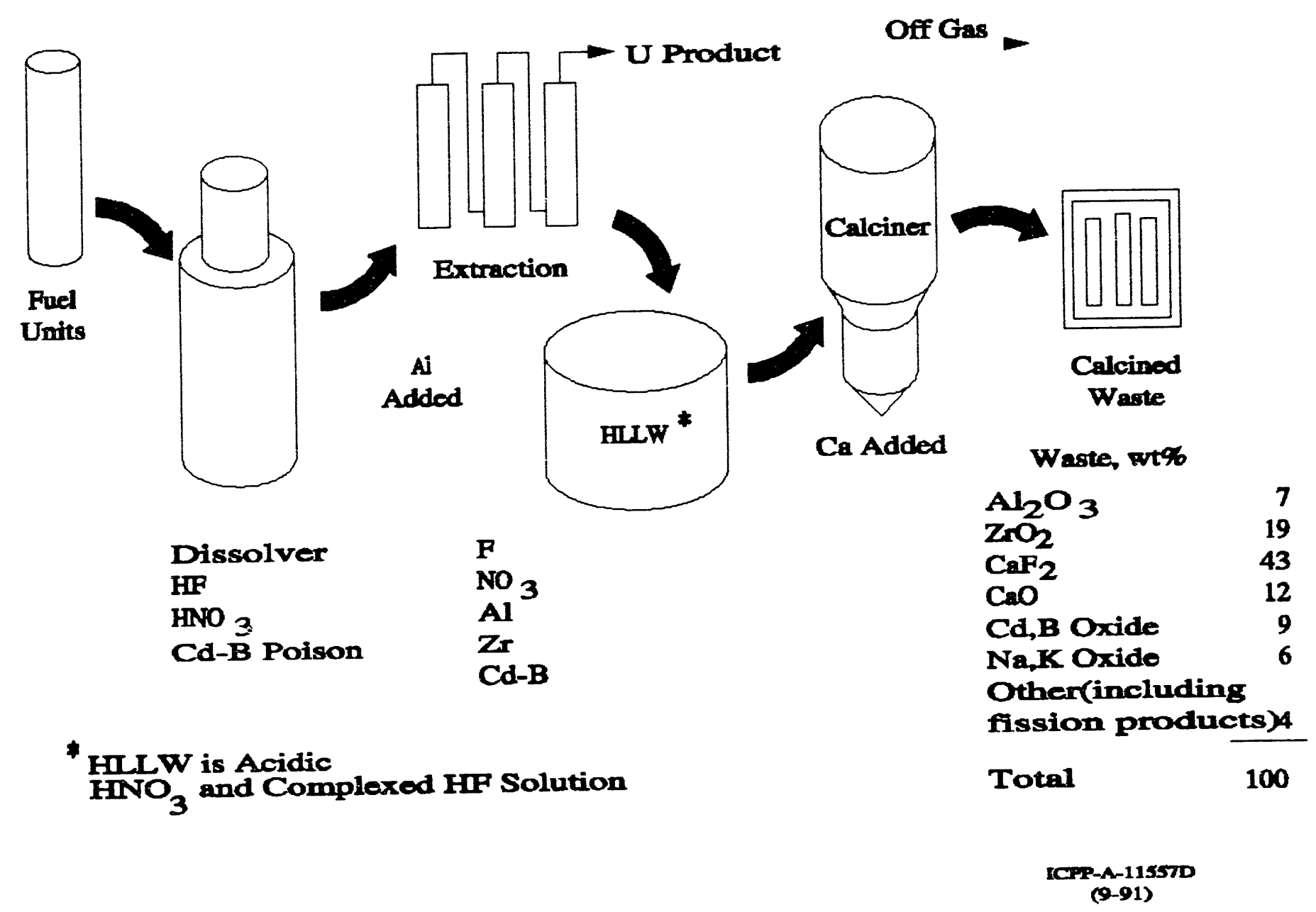

Figure 1-1. Source of HLW from Fuel Processing at ICPP 
200 and $10 \mu \mathrm{m}$ in diameter. As expected from fuel reprocessing history, several types of calcine exist; the predominant amount contains about $50 \mathrm{wt} \%$ $\mathrm{CaF}_{2}$ and $50 \mathrm{wt} \%$ of metal oxides such as $\mathrm{Al}_{2} \mathrm{O}_{3}, \mathrm{ZrO}_{4}$, and $\mathrm{B}_{2} \mathrm{O}_{3}$. The total radionuclide content is less than $1 \mathrm{wt} \%$.

The comprehensive report of Berreth (1988) presents an excellent summary of data concerning the inventory, content of both radiochemical and inert chemicals, and physical properties of the various types of calcine. Berreth also provides figures which depict the stratification of calcine types in various bin sets. Relevant tables and figures from Berreth's document are reproduced in Appendix $A$ of this report.

\subsection{FINAL DISPOSAL OF ICPP CALCINE-ALTERNATIVE APPROACHES}

Interim storage of the ICPP calcine in the solid storage bins currently meets all applicable safety criteria and regulations. Eventually, however, it will be necessary to retrieve the calcine and convert it to a form suitable for transportation to and disposal at a deep geologic federal repository. Experimental work completed to date with simulated calcine indicates that it can be converted to either a borosilicate glass or a glass-ceramic form for final disposal (Berreth and knecht 1986).

An alternative approach for final disposal of the retrieved calcine is to partition it, by appropriate chemical processes, into a low-level waste fraction and a much smaller volume of high-level waste. The goal of a such a partitioning approach is to produce a low-level waste which is entirely suitable, after conversion to an immobile form, for near-surface disposal per 10 CFR 61. The small volume of high-level waste containing the radionuclides separated from the calcine can then be converted to a form suitable for disposal in a federal geologic repository. Economic advantages may accrue as the result of greatly reducing the number of high-level waste containers (e.g., canisters of glass) which must be transported to and disposed of at an off-site federal repository. Certainly, thorough and efficient decontamination of the low-level waste fraction of the calcine from radionuclides will make its final near-surface disposal much more environmentally and politically acceptable to all concerned stakeholders. 


\subsection{DEFINITION AND SELECTION OF RADIONUCLIDE PARTITIONING TECHNOLOGY}

Nearly 50 years of research and development as well as extensive plant-scale experience in the U. S. and in many other countries has produced a wealth of processes and technologies which can be potentially applied to separate various radionuclides from aqueous acidic and alkaline media. From this vast array of available technology, selection of the most appropriate separations processes to test and develop for potential application to the ICPP calcine is indeed a formidable challenge.

To help them in their initial screening, evaluation, and selection of processes to be tested, Westinghouse Idaho Nuclear $C_{0}$. officials convened a panel of knowledgeable nuclear separations specialists (Appendix B). This panel met for four days in February (16-19), 1993 at Idaho State University in Pocatel10, Idaho to:

- Discuss and decide which radionuclides to partition and to what extent.

- Review the small amount of experimental data available pertaining to water leaching of ${ }^{137} \mathrm{Cs}$ from calcine and to dissolution of the calcine in $\mathrm{HNO}_{3}$.

- List, discuss, and rank all known liquid-liquid extraction, ion exchange (both inorganic and organic sorbents), extraction chromatographic, and precipitation processes for their potential application to removal of TRU elements, ${ }^{90} \mathrm{Sr},{ }^{99} \mathrm{Tc},{ }^{129} \mathrm{I}$, and ${ }^{137} \mathrm{Cs}$ from $\mathrm{HNO}_{3}$ solutions of ICPP calcine. Processes for removal of ${ }^{137} \mathrm{Cs}$ from alkaline solutions were also evaluated and ranked.

- Generate conceptual process flow diagrams for radionuclide removal based upon the higher rated separations processes.

- For the selected suite of separations processes, provide a generic but detailed list of important process variables and parameters to be investigated in bench-scale tests with both simulated and actual ICPP calcine.

- Formally document important discussions, findings, and recommendations arising from the February 16-19, 1993 meeting in Pocatello, Idaho. This report meets this latter commitment. 


\subsection{ASSUMPTIONS AND BASES}

This document was prepared in accord with the following bases and assumptions .

- Candidate radionuclides to be partitioned from the ICPP calcine are limited to: ${ }^{90} \mathrm{Sr},{ }^{99} \mathrm{Tc},{ }^{129} \mathrm{I},{ }^{137} \mathrm{Cs},{ }^{237} \mathrm{~Np},{ }^{239} \mathrm{Pu}$, and ${ }^{241} \mathrm{Am}$. These radionuclides are those which have either a long half life (Tc, I, Np, $\mathrm{Pu}$, and $\mathrm{Am})$, are known to be easily transported in the environment (Tc, I, and $\mathrm{Np}$ ), are major heat producers ( $\mathrm{Sr}$ and $\mathrm{Cs}$ ), or are major contributors to the radiation dose of the calcine ( $\mathrm{Sr}$ and $\mathrm{Cs}$.)

- Concentrations of candidate radionuclides to be removed will be reduced to or below the criteria stated by the Nuclear Regulatory Commission for classification of the residual waste as a Class A waste (NRC 1988). The goal of the radionuclide partitioning process is to produce a residual waste which, after conversion to a suitable form, meets all applicable regulations for safe and final disposal.

- Removal of certain long-lived radionuclides, e.9.. ${ }^{79} \mathrm{Se}^{93} \mathrm{Zr}$. ${ }^{107} \mathrm{Pd},{ }^{151} \mathrm{Sm}$, and ${ }^{128} \mathrm{Sn}$, expected to be present in small concentrations in the ICPP calcine, will not be necessary to achieve a waste suitable for disposal.

- Only aqueous-based processes are considered to accomplish dissolution of the calcine and subsequent separation of candidate radionuclides. Nonaqueous separations processes, e. g., pyrochemical and volatilization, which might be applied to remove, at least in part, certain radionuclides, e.g., ${ }^{137} \mathrm{Cs}$ and ${ }^{129} \mathrm{I}$, or certain inert constituents, e.g., $A 1$ and $Z r$, are the subject of other studies and are outside the scope of this report.

- Except for ${ }^{137} \mathrm{Cs}$, candidate separations process are limited to those which operate with acidic $\left(\mathrm{HNO}_{3}\right)$ feed solutions. However, processes which separate ${ }^{137} \mathrm{Cs}$ from either acidic or alkaline feed solutions are addresser. ${ }^{137} \mathrm{Cs}$ and ${ }^{99} \mathrm{TC}$ are soluble in both acidic and alkaline solutions; the other candidate radionuclides have only 1 imited solubility in alkaline media.

- Iransuranium (TRU) elements partitioned from dissolved calcine will not be separated from associated radioactive or inert lanthanide 
elements. Separation of trivalent actinides from trivalent lanthanides is a difficult and expensive task and is not required for cost-effective disposal of the partitioned TRU elements.

- Separated radionuclides will be combined and incorporated into a glass or glass-ceramic form for final disposal in an off-site deep geologic repository.

- Separations processes which either singly or in combination do not generate large amounts of secondary waste streams are preferred over other separations technology. 


\subsection{DESCRIPTION OF APPLICABLE SEPARATIONS TECHNOLOGY}

\subsection{INTRODUCTION}

The first important task accomplished by the Panel of Nuclear Separations Experts was to list and discuss what panel members believe to be appropriate and usable chemical processes for removing TRU elements, ${ }^{90} \mathrm{Sr},{ }^{99} \mathrm{Tc},{ }^{137} \mathrm{Cs}$, and, if present, ${ }^{129} \mathrm{I}$ from $\mathrm{HNO}_{3}$ solutions of ICPP calcine.

For discussion purposes, the listed processes group naturally into four kinds of separations technologies and unit operations, namely:

- Liquid-1iquid extraction

- Sorption-both Organic and Inorganic Sorbents

- Extraction Chromatography

- Precipitation

\subsection{LIQUID-LIOUID EXTRACTICN PROCESSES}

\subsubsection{Transuranium Elements}

Both monofunctional and bifunctional reagents are available for extraction of $\mathrm{Am}$ (III), $\mathrm{Pu}(\mathrm{IV}, \mathrm{VI})$, and also $\mathrm{Np}$ (IV,VI) from acidic nuclear waste solution. Typical monofunctional extractants for this purpose include:

TBP tributylphosphate

HDEHP bis-2-ethylhexylphosphoric acid

DBBP dibutylbutylphosphonate

DIDPA di-isodecylphosphoric acid

All the monofunctional reagents efficiently extract +4 and +6 actinide elements from strong (i.e., $>1 \mathrm{M} \mathrm{HNO}_{3}$ ) media. Several also extract +3 actinide elements, but only under weakly acidic, e.g., $0.01 \mathrm{M}$ to $0.5 \mathrm{M} \mathrm{HNO}_{3}$, conditions. Routine plant-scale control of feed acidity in the range $0.01 \mathrm{M}$ to $0.5 \mathrm{M} \mathrm{HNO}_{3}$ in an unbuffered system could be tedious and difficult. There is also great danger that hydrous metal oxides, e.g., $\mathrm{Fe}_{2} \mathrm{O}_{3} \cdot \mathrm{H}_{2} \mathrm{O}$, which will scavenge $\mathrm{Pu}(\mathrm{IV})$ and other actinides, will precipitate during feed acidity adjustments. 
Because they contain two functional groups in the same molecule, certain bifunctional organic compounds are able to extract $A m(I I I)$ as well as +4 and +6 actinides very efficiently from strong $\mathrm{HNO}_{3}$ (i.e., >0.5 M) solutions. The presence of two functional groups in these compounds provides sort of an internal buffering regime which eliminates or, at least greatly reduces, competition from $\mathrm{HNO}_{3}$ for extractant molecules.

Three classes of bifunctional extractants for $+3,+4$, and +6 actinides from strong $\mathrm{HNO}_{3}$ media are currently known:

- Carbamoy1methylphosphonates, e.g., DHDECMP (dihexyl-N, $\mathrm{N}$-diethylcarbamoylmethylphosphonate)

- Carbamoylmethylphosphine oxides, e.g., CMPO (octy1- (pheny1)-N, $\mathrm{N}$-di isobutylcarbamoylmethylphosphine oxide)

- Diamides

Very detailed studies of the synthesis and chemical and physical properties of the former two classes of bifunctional extractants have been performed in the U.S. A comprehensive report summarizing present knowledge of carbamoylmethylphosphonate and carbamoylmethylphosphine oxide actinide extractants has been recently issued (WHC-EP-0577, 1993).

The French under the leadership of Dr. C. Musikas at their Fontenay-aux-Roses Laboratories have developed a series of diamides which extract +3 actinides as well as +4 and +6 actinides from 3-6 $\mathrm{M} \mathrm{HNO}_{3}$ solutions. Several potentially useful diamides have been prepared and their actinide extraction properties determined. But, work is still in progress to find the optimum diamide and diluent for potential plant-scale application. Typically, the French have used $0.5 \mathrm{M}$ solutions of various diamides in hydrogenated propylene tetramer (HPT). With such systems, problems have been encountered from formation of a third (second organic) phase when the diamide is loaded with metal ions. Perhaps the greatest current difficulty with diamide compounds is that they appear to be particularly susceptible to hydrolysis when in contact with aqueous $\mathrm{HNO}_{3}$ solutions. 
Advantage of the strong actinide extraction properties of CMPO is taken in the TRUEX (Transuranium Extraction) process. The TRUEX process typically utilizes a $0.2 \mathrm{M}$ solution of CMPO in 1.2 to $1.4 \mathrm{M}$ TBP (tributyl phosphate) and NPH (Normal Paraffin Hydrocarbon, a commercially-available mixture of $C_{9}$ to $C_{14}$ normal alkanes). Addition of TBP to the CMPO-NPH organic phase offers a convenient way of avoiding third phase formation in practical applications. The TRUEX process has been tested on both small continuous countercurrent and batch scales with both simulated and actual waste solutions in nuclear laboratories around the world including the U. S., India, Italy, Japan, and Canada. In all cases, highly satisfactory results have been obtained; aqueous raffinates containing very low, e.g., $<10 \mathrm{nCi} /$ gram of waste, concentrations of TRU elements have been routinely achieved.

To suppress co-extraction of feed impurities such as $\operatorname{Zr}$ (IV) and Fe(III), conventional practice is to add oxalic acid to the feed solution to complex such elements. By judicious choice of stripping agents, the TRUEX process can be operated to selectively partition +3 actinides from +4 and +6 actinides and +4 actinides from +6 actinides. Alternatively, all actinides can be costripped using complexing stripping agents. Also, stripping agents such as sodium carbonate or ammonium carbonate solutions will effectively costrip all actinides and also remove acidic solvent degradation products.

Actinide element extraction processes based upon use of DHDECMP can also be applied to removal of actinide elements from strong $\mathrm{HNO}_{3}$ solutions. But, because DHDECMP is a weaker extractant than is CMPO, a process using DHDECMP will require either a higher concentration of organic extractant, more stages, a higher organic-to-aqueous phase ratio or all three modifications to accomplish the same degree of actinide removal as one based upon use of CMPO. But, by the same token, compared to say a 0.2 M CMPO solution, a 0.2 M DHDECMP solvent extracts substantially less $\mathrm{Zr}$ (IV) and $\mathrm{Fe}$ (III); it is also much easier to strip actinides from a $0.2 \mathrm{M}$ DHDECMP solvent than from a $0.2 \mathrm{M} \mathrm{CMPO}$ solvent. 


\subsubsection{Cesium and Strontium}

Czechoslovakian and, later, Russian scientists have extensively investigated the properties of the inorganic compound cobalt dicarbollide, dissolved in a polar diluent such as nitrobenzene, for extracting ${ }^{137} \mathrm{Cs}$ from 1 $\mathrm{M} \mathrm{HNO}_{3}$ solutions (Rais, Selucky, and Kyrs 1976). "The dicarbollide radiocesium extraction process involves extraction of $\mathrm{Cs}^{+}$as an ion pair with the dicarbollide (or chlorinated derivative of dicarbollide) anion. Strong acid, i.e., >3 $\mathrm{M} \mathrm{HNO}_{3}$, solutions must be used to strip cesium from the dicarbollide solvent. Russian workers report that they have synthesized kilogram quantities of cobalt dicarbollide and have used the cobalt dicarbollide extraction process to remove/recover megacuries amounts of ${ }^{137} \mathrm{Cs}$ from PUREX process high level waste.

The Eastern European scientists/engineers have also discovered that addition of an aqueous-soluble polyethylene glycol to $1 \mathrm{M} \mathrm{HNO}_{3}$ feeds promotes satisfactory extraction of ${ }^{90} \mathrm{Sr}$ by solutions of cobalt dicarbollide in a polar diluent. Again, >3 $\mathrm{M} \mathrm{HNO}_{3}$ solutions strip extracted ${ }^{90} \mathrm{Sr}$.

A recent report (LA-11695, 1992), although containing a few inaccuracies, summarizes most of the current published information about cobalt dicarbollide and its use as an extractant for ${ }^{137} \mathrm{Cs}$ and ${ }^{90} \mathrm{Sr}$. The referenced report also mentions that all of the polar diluents currently recommended for use in the dicarbollide extraction process are toxic compounds, by today's standards, and are, therefore, not acceptable for use in plant-scale nuclear separations processes. At a recent (February 23-26, 1993) DOE-sponsored joint US-Russian meeting on the cobalt dicarbollide extraction process, the U.S. scientists/engineers again cited the toxic properties of candidate polar diluents as the prime obstacle to serious US consideration of the dicarbollide extraction process for plant-scale application. Other uncertainties concerning the plant-scale applicability of the dicarbollide extraction process include: (1) compatibility of dicarbollide and TRU-element extraction process solvents; (2) radiolytic degradation products of chlorinated dicarbollide extractants and their corrosivity; and (3) effects of large amounts of feed components such as $\mathrm{Zr}$ (IV) and Ca(II) upon dicarbollide extraction process performance. 
Horwitz and coworkers at the Argonne National Laboratory (Horwitz, Dietz, and Fisher 1990) have recently developed the SREX (Strontium Extraction) process for selective extraction of ${ }^{10} \mathrm{Sr}$ from highly acidic aqueous solutions. The SREX process utilizes a particular crown ether, $4,4^{\prime}\left(5^{\prime}\right)$-bis (tertbutylcyclohexano)-18 crown-6, dissolved in a suitable diluent. Initial development tests emphasized n-octanol as a suitable diluent; later studies indicated that a mixture of TBP and NPH is also a suitable diluent for the crown ether.

Bench-scale studies by Horwitz, et al. show that: (1) the SREX process selectively extracts ${ }^{90} \mathrm{Sr}$ in the presence of large amounts of $\mathrm{Ca}^{2+}$; only $\mathrm{Ba}^{2+}$ and $\mathrm{TC}$ (VII) compete with ${ }^{90} \mathrm{Sr}$ for the ether extractant; (2) dilute $\mathrm{HNO}_{3}$ solutions readily strip extracted ${ }^{90} \mathrm{Sr}$; and (3) the SREX process solvent is satisfactorily resistant to radiolytic and hydrolytic attack. Several batch-scale tests of the SREX process with actual nuclear waste solution have been conducted; in one test with LWR fuel reprocessing waste, three successive batch contacts of a waste solution, from which TRU elements were previously removed, provided an overall ${ }^{90} \mathrm{Sr}$ decontamination factor of 4500 (WHC-EP-0268 1990).

An interesting new development is the combination of the TRUEX and SREX process solvents to yield a solvent containing CMPO-crown ether-TBP-NPH and which is capable of coextracting TRU elements, ${ }^{90} \mathrm{Sr}$, and ${ }^{99} \mathrm{Tc}$. This so-called combined process has been successfully tested by Horwitz and coworkers with simulated radioactive waste solutions. Tests of the combined process with actual waste remain to be performed.

\subsubsection{Technetium}

Both the TRUEX and the SREX processes can extract ${ }^{99} \mathrm{TC}\left(\right.$ as $\left.\mathrm{HTCO}_{4}\right)$ from acidic feed solutions. For efficient ${ }^{99} \mathrm{Tc}$ extraction by the TRUEX process solvent, the feed acidity needs to be maintained at or below $1 \mathrm{MHNO}_{3}$. Dilute sodium (or ammonium) carbonate solutions effectively strip ${ }^{99}$ Tc from both the TRUEX and SREX process solvents; dilute acid strips ${ }^{99}$ Tc from the SREX solvent. Of course, the combined TRUEX-SREX process solvent provides 
excellent coextraction of ${ }^{99} \mathrm{TC}$ as well as TRU elements and ${ }^{90} \mathrm{Sr}$ from acid feeds.

\subsubsection{Iodine}

Proven liquid-liquid extraction process technology for removal of ${ }^{129} I$ from aqueous acid or alkaline feed solutions is not available. Rather, it is believed that the required removal of ${ }^{129}$ I from ICPP calcine can best be accomplished by volatilization of iodine during dissolution of the calcine in $\mathrm{HNO}_{3}$. Any residual $\mathrm{I}_{2}$ in the feed to a $-2 \mathrm{U}$-element solvent extraction process would, however, extract to the organic phase. Addition of nitrite ion to the aqueous feed prior to TRU element extraction may be desirable to enhance extraction of $I_{2}$, Extracted $I_{2}$ would be stripped from the solvent by $a$ carbonate wash solution.

\subsection{ION EXCHANGE TECHNOLOGY}

\subsubsection{Iransuranium Elements}

Both organic cation and anion-type exchangers have been applied for removal of TRU elements from nuclear waste solutions. Thus, well-known anionic resin technology has long been used to selectively sorb, concentrate, and purify neptunium and/or plutonium from 7-8 $\mathrm{M} \mathrm{HNO}_{3}$ solutions. Organic anion resins do not, however, efficiently sorb $\mathrm{Am}$ (III) from $\mathrm{HNO}_{3}$ solutions. Organic cation resins strongly sorb +3 and +4 TRU elements from weakly acid $\left(<0.5 \mathrm{M} \mathrm{HNO}_{3}\right)$ nuclear waste solutions. Unfortunately, these resins also strongly sorb all other +3 and +4 cationic impurities, e.g., Fe(III), Al(III), $\mathrm{Zr}$ (IV), etc. as well as +2 cations, e.g., $\mathrm{Ca}^{2+}$. Thus, in contrast to organic anion exchange resins, which are too selective, organic cation exchange resins are not selective enough for sorbing TRU elements.

Many inorganic ion exchange materials have been investigated for their ability to sorb TRU elements from both alkaline and acid solutions. The list of such inorganic sorbents includes sodium titanate, sodium zirconate, sodium niobate, zirconium phosphate, $\mathrm{TiO}_{2}$ - and $\mathrm{ZrO}_{2}$-impregnated cation exchange resins, and crystalline silicotitanate (CST) (WHC-EP-0577 1993). Aside from 
the CST material which is currently being intensively studied, none of the known ion exchangers sorb TRU elements significantly at solution $\mathrm{pH}^{\prime} \mathrm{s}$ less than about 2. Some preliminary results (Brown 1993) suggest that CST will effectively sorb TRU elements from $1 \mathrm{M} \mathrm{HNO}_{3}$ solutions. Currently, no way is known of eluting TRU elements from CST materials without at least partial destruction of the CST exchangers. Economic and other factors involved in converting TRU element-loaded CST to a glass or a ceramic form for final disposal need to be evaluated.

\subsubsection{Cesium}

\section{Acid Solutions}

There are no known organic-based ion exchange resins which can be used for efficient removal of ${ }^{137} \mathrm{Cs}$ from strongly $\left(>0.5 \mathrm{M} \mathrm{HNO}_{3}\right)$ acidic media.

Inorganic sorbents that show promise for removal of ${ }^{137} \mathrm{Cs}$ from acidic media include CST; metal ferrocyanides; zirconium phospilate; titanium phosphate; ammonium phosphotungstate; ammonium phosphomolybdate; and various zeolites (Kolarik 1991). Concerns, likely invalid because the formation of dry nitrate salts on the sorbent could be prevented with proper engineering controls, about the safety of metal ferrocyanide sorbents in a nitrate-based media would likely preclude their use. Except for zeolite sorbents, which have been reported (Kolarik 1991) to sorb ${ }^{137} \mathrm{Cs}$ from $0.45 \mathrm{M} \mathrm{HNO}_{3}$ solutions, none of the other candidate inorganic sorbents are available in a form suitable for column-type operations. A concern with all the candidate inorganic sorbents is the extent to which $\mathrm{Zr}$ (IV), $\mathrm{AI}$ (III), and $\mathrm{Ca}$ (II) in solution would compete with ${ }^{137} \mathrm{C}$ s for sorption sites; bench-scale studies to determine the extent of such competition are necessary.

\section{Alkaline Solutions}

The need or desire to remove ${ }^{137} \mathrm{Cs}$ from alkaline media in partitioning of ICPP calcine may arise in two instances. For example, removal of ${ }^{137} \mathrm{Cs}$ from neutral or alkaline water leaches of the calcine may have process incentives. It may also be beneficial, following removal of TRU elements, ${ }^{99} \mathrm{Tc},{ }^{90} \mathrm{Sr}$, and ${ }^{129}$ I from acidic media, to neutralize the acid raffinate and remove ${ }^{137} \mathrm{Cs}$ from the alkaline supernatant liquor. 
Both naturally-occurring and synthetic zeolites have been used on a plant-scale to remove ${ }^{137} \mathrm{Cs}$ from alkaline waste solutions. For example, Ionsiv-95 was used to remove ${ }^{137} \mathrm{Cs}$ from reactor coolant and containment building water during cleanup of Three Mile Island Reactor 2. Zeolite sorbents are currently being used to remove ${ }^{137} \mathrm{Cs}$ from the West Valley (New York) site alkaline wastes. Recently, also in the United Kingdom, British Nuclear Fuels Limited uses a natural zeolite (clinoptilolite) for sorbing ${ }^{137} \mathrm{Cs}$ from certain alkaline wastes. And, earlier (1960's) Zeolon-900, a naturally-occurring zeolite was used at the DOE Hanford site to sorb ${ }^{137} \mathrm{CS}$ from certain alkaline waste solutions.

A disadvantage of zeolites for removing ${ }^{137} \mathrm{Cs}$ from alkaline solutions is that sorbed cesium cannot be easily eluted. In plant-scale practice at the Hanford site, aqueous solutions containing high concentrations of ammonium carbonate were used to elute ${ }^{137} \mathrm{Cs}$ from Zeolon-900 zeolite; extensive heat treatment of the eluate was necessary to recover and regenerate ammonium carbonate for reuse. In many applications, Cs-loaded zeolite beds are simply vitrified and disposed of as high-level waste. The economics of this practice must be evaluated for each particular application.

Aside from zeolites, most of the inorganic materials already mentioned, e.g., metal ferrocyanides, CST, zirconium phosphate, titanium phosphate, pillared clays, etc., as candidates for removal of ${ }^{137} \mathrm{Cs}$ from acid media are al so suitable for sorption of ${ }^{137} \mathrm{Cs}$ from alkaline waste solutions. Save for zeolites and, possibly, CST, safety and other concerns, e.g., non-availability of forms suitable for column-type operation, prevent serious consideration of many of the inorganic materials for large-scale use. CST is known to have a high affinity for ${ }^{137} \mathrm{Cs}$ from alkaline media. Issues still to be resolved with CST include: 1) identification of manufacturing techniques for producing a form hydraulically suitable for column-type operation, 2) technology for eluting sorbed ${ }^{137} \mathrm{CS}$, and/or 3 ) determination of the economics of disposal of the CS loaded CST.

Phenolic-based organic cation exchangers have lorig been known for their ability to selectively sorb ${ }^{137} \mathrm{Cs}$ from alkaline waste solutions. At the Hanford site, for example, a phenolic-based resin (Duolite ARC-359) was used 
in the $1960^{\prime} s$ to routinely separate megacuries of radiocesium from a wide variety of stored alkaline wastes (Schulz and Bray 1987). Concentrated ammonium carbonate solutions were used to elute the sorbed ${ }^{137} \mathrm{Cs}$ in the Hanford site application. Currently at the Hanford site, a phenolic-based cation exchange resin, CS-100 (Rohm \& Haas Co.) is specified for eventual use in further plant-scale removal of ${ }^{137} \mathrm{Cs}$ from wastes to be disposed of as low-level waste. An advantage of the CS-100 resin is that dilute $\mathrm{HNO}_{3}$ solutions can be safely used to elute sorbed cesium.

Workers at the DOE Savannah River Site have recently developed a resorcinol-based organic cation exchange resin for removal of ${ }^{137} \mathrm{Cs}$ from alkaline wastes (DPST-87-647, 1987). The resorcinol-based exchanger has a greater capacity for ${ }^{137} \mathrm{Cs}$ than conventional phenolic-based resins and also has greater selectivity for ${ }^{137} \mathrm{Cs}$ over sodium. Batch-scale and small column tests of the resorcinol-based resin with Hanford, Savannah River, and Oak Ridge site wastes have been conducted, all with good results. The resorcinol-based resin is not yet commercially available, but conditions for its preparation have been demonstrated on a large-scale.

\subsubsection{Strontium}

Sodium titanate, an inorganic material, is well known for its high affinity for sorbing small concentrations of ${ }^{90} \mathrm{Sr}$ from highly alkaline media. But, sodium titanate does not appear to sorb ${ }^{90} \mathrm{Sr}$ from solutions whose $\mathrm{pH}$ is <2. It is not yet known if CST, currently in the development and testing stage, will effectively sorb ${ }^{90} \mathrm{Sr}$ from solutions whose $\mathrm{pH}$ is $<2$. No simple way of eluting ${ }^{90} \mathrm{Sr}$ from titanate materials has yet been identified.

Antimonic acid selectively and strongly sorbs ${ }^{90} \mathrm{Sr}$ from 0.5 to $5 \mathrm{M} \mathrm{HNO}_{3}$ solutions (Kolarik 1991). Potential plant-scale application of this sorbent is hampered by its commercial unavailability in a form suitable for column-type operations without excessive pressure drop and by lack of simple ${ }^{90} \mathrm{Sr}$ eluent and elution conditions. 


\subsubsection{Technetium}

Technetium exists in the stable pertechnetate, $\mathrm{TcO}_{4}{ }^{\circ}$, ion in either aqueous acidic or alkaline media. The classic and long-established method of removing ${ }^{99} \mathrm{Tc}$ from such solutions is to sorb $\mathrm{TCO}_{4}$ on either strong or weak base anion exchange resins (Kolarik 1991). Sorbed $\mathrm{TCO}_{4}{ }^{-}$is eluted only with difficulty from such resins; typically, 3 to $9 \mathrm{M} \mathrm{HNO}_{3}$ solutions are used as the technetium eluent. If present, rhodium and palladium species are also reported (Kolarik 1991) to co-sorb with technetium on anion exchange resins.

\subsection{EXTRACTION CHROMATOGRAPHIC TECHNOLOGY}

\subsubsection{Introduction}

Extraction chromatography is a separations process that combines the selectivity of solvent extraction with the simplicity and multistage attributes of traditional fixed-bed chromatographic systems. Conventional solvent extraction systems are liquid-liquid systems; in extraction chromatographic processes, the same separations are accomplished in a solid-liquid system. Advantages sometimes claimed for extraction chromatographic systems over liquid-liquid extraction systems include the use of simple process equipment and lower capital costs for process equipment. Despite these perceived advantages, to date, extraction chromatographic systems have not been selected to accomplish plant-scale nuclear separations processes.

Extraction chromatographic resins are typically prepared by sorbing known and proven extractants on a nonporous polymeric support. This preparation scheme yields a product which fixes the extractant while retaining its favorable chemical properties, e.g., distribution ratios and selectivity.

\subsubsection{Iransuranium Elements}

Development of extraction chromatographic materials and technology for removal of $A m$ (III) and other TRU elements from strongly acidic solutions followed soon after properties of bifunctional organophosphorus extractants 
had been determined. For example, Barney and Cowan (1992) utilized EIChrom Industries TRU.Spec resin in their extraction chromatographic studies of removal of TRU elements from simulated acidified Hanford wastes. These workers found, as expected, that columns containing TRU.Spec resin would sorb both Pu(IV) and Am(III) from such solutions. Both the selectivity and capacity of the TRU.Spec resin were adversely affected by cosorption of $\mathrm{HNO}_{3}$ and various impurity metal ions including $\mathrm{Zr}$ (IV), $\mathrm{Fe}$ (III), and U(VI). Barney and Cowan did not investigate beneficial effects, if any, of adding oxalic acid to feed solutions to minimize uptake of impurity metal ions.

Prior to the recent work of Barney and Cowan, Yamada et al. (1982) at the DOE Rocky Flats site performed bench-scale extraction chromatographic tests of the sorption of gram amounts of ${ }^{241} \mathrm{Am}$ from waste solutions on columns containing DHDECMP sorbed onto Amberlite XAD-4 ${ }^{b}$; no plant-scale application of this technology was ever made.

Even earlier, French scientists at the Fontenay-aux-Roses site developed and utilized extraction chromatographic techniques for recovery of ${ }^{241} \mathrm{Am}$ and other actinides from nitrate-based aqueous wastes (Madic et al 1980). The French process performed extraction chromatography of neptunium, plutonium, and americium on a silica gel column containing di-n-hexyloctoxymethylphosphine oxide. Madic and his colleagues also tested use of silica gel containing sorbed CMPO for extraction chromatographic removal of ${ }^{241} \mathrm{Am}$ from waste solutions generated in French nuclear operations.

\subsubsection{Strontium}

Nearly coincident with the announcement of the SREX process, Horwitz and his colleagues at the Argonne National Laboratory developed an extraction chromatographic material for removal of ${ }^{90} \mathrm{Sr}$ from strong $\mathrm{HNO}_{3}$ solutions (Horwitz, Chiarizia, and Dietz 1992). This material was prepared by sorbing a

a TRU.Spec resin, made by EIChrom Industries, Inc., Naperville, Illinois, contains a mixture of CMPO and TBP sorbed onto a macroporous polymeric support $(13,27$, and $60 \mathrm{wt} \%$, respectively).

b Amberite XAD-4 ij a trademark of Rohm \& Haas Co. 
solution of $4,4^{\prime}\left(5^{\prime}\right)$-bis(t-butylcyclohexano)-18-crown-6 (DtBuCH18C6) in 1 -octanol on an inert polymeric substrate.

An extraction chromatographic material based upon the work of Horwitz et a1. is marketed commercially by EIChrom Industries under the name Sr.Spec. Much use of the $\mathrm{Sr}$. Spec sorbent has been made to conduct rapid and selective analysis for ${ }^{90} \mathrm{Sr}$ in a wide range of biological, environmental, and other materials.

Bench-scale tests to investigate application of the Sr.Spec resin for plant-scale removal of ${ }^{90} \mathrm{Sr}$ from acidic nuclear waste solutions have not been performed. But, because the Sr.Spec materials utilize the same organic extractant used in the SREX process, there does not appear to be any technical reason why it should not be useful in removing ${ }^{90} \mathrm{Sr}$ from acidified ICPP calcine. Assuming equal technical feasibility, a choice between the solvent extraction SREX process and the extraction chromatographic process for removal of ${ }^{90} \mathrm{Sr}$ from $\mathrm{HNO}_{3}$ solutions of ICPP calcine must be based upon the outcome of comprehensive engineering and economic analyses yet to be done.

\subsubsection{Cesium}

Development of extraction chromatographic processes for removal of ${ }^{137} \mathrm{Cs}$ from acidic solutions is just in its infancy. Such materials require organic extractants with a strong affinity for ${ }^{137} \mathrm{Cs}$ in strong $\mathrm{HNO}_{3}$ solutions. Candidate extractants, e.g., various crown ethers and, perhaps, cobalt dicarbollide, are just now being intensively studied.

Scientists at the Brigham Young University in Utah have recently formed a small company (IBC Corporation) to market a Cs-specific extraction chromatographic material (a crown ether on a siliceous matrix.) Extensive tests of the so-called "Molecular Recognition" material with actual waste solutions have not been performed.

Attempts to prepare Cs-specific extraction chromatographic materials by incorporation of crown ethers into organic resins characteristic of those sold by EIChrom Industries have not been done or, at least, have not been reported. 


\subsubsection{Technetium}

It was pointed out earlier that both the TRUEX and SREX extractants will, at appropriate feed $\mathrm{HNO}_{3}$ concentrations, co-extract ${ }^{99} \mathrm{TC}$ with TRU elements or ${ }^{90} \mathrm{Sr}$. Thus, both the EIChrom Industries products TRU.Spec and Sr.Spec which utilize, respectively, TRUEX and SREX process solvents, will sorb ${ }^{99}$ Tc from acid feed solutions. Detailed bench-scale scudies to establish optimum conditions for uptake and removal of ${ }^{99} \mathrm{TC}$ from the TRU.Spec and Sr.Spec sorbents have not been performed. Such studies are needed to determine the technical feasibility of extraction chromatographic removal of technetium from acidified ICPP calcine.

\subsubsection{Iodine}

No extraction chromatographic materials or processes for removal of ${ }^{129} \mathrm{I}$ from either acidic or alkaline solutions are known.

\subsection{PRECIPITATION - COPRECIPITATION TECHNOLOGY}

\subsubsection{Introduction}

Considering their extensive use in quantitative analysis, it is not surprising that precipitation processes and/or co-coprecipitation processes have been devised for almost all TRU elements and fission products. Indeed, the very first large scale nuclear separations process-- $\mathrm{BiPO}_{4}$ process--involved co-precipitation of $\mathrm{PU}(\mathrm{IV})$ and bismuth by addition of $\mathrm{Bi}\left(\mathrm{NO}_{3}\right)_{3}$ and phosproric acid to a $\mathrm{HNO}_{3}$ solution of irradiated uranium metal.

For plant-scale radionuclide partitioning applications there are three important disadvantages and objections to precipitation processes. These disadvantages are:

- Time-consuming batch rather than continuous operation.

- Difficulty and complexity of performing solid-liquid separations to rigorous specifications for solids carryover. 
- Inability, usually, of realizing extremely high, i.e., $99.9+\%$, removal of particular radionuclides in a single precipitation step.

Nevertheless, in some cases, a precipitation process is still the most effective way to achieve a difficult and/or selective separation of a radionuclide. For that reason and also because they require low-cost equipment, the Panel believes that it is proper to include precipitation processes in the overall suite of unit operations and processes applicable to removal of radionuclides from ICPP calcine.

\subsubsection{TRU Elements}

Plutonium(IV) and also $\mathrm{Np}$ (IV) coprecipitate when $\mathrm{BiPO}_{4}$ is precipitated at about $\mathrm{pH} \mathrm{1.} \mathrm{This} \mathrm{coprecipitation} \mathrm{scheme} \mathrm{formed} \mathrm{the} \mathrm{basis} \mathrm{of} \mathrm{the} \mathrm{BiPO}_{4}$ process used in the early days of the nuclear separations industry to separate and decontaminate weapons-grade plutonium. Americium(III) does not coprecipitate with $\mathrm{BiPO}_{4}$ to any great degree. Because of solubility limitations, coprecipitation of $\mathrm{Pu}(\mathrm{IV})$ and/or $\mathrm{Np}$ (IV) with $\mathrm{BiPO}_{4}$ is not quantitative. Impurity elements such as $\mathrm{Zr}$ (IV), which form insoluble phosphates, coprecipitate with plutonium and/or neptunium.

Oxalates of $\mathrm{Np}$ (IV), $\mathrm{Pu}$ (III,IV), and $\mathrm{Am}$ (III) are all fairly insoluble in $1 \mathrm{M} \mathrm{HNO}_{3}$. Thus, much use of oxalate precipitation schemes, both in analytical and in plant-scale processes, has been made. Purified plutonium in nitrate media is often converted to plutonium oxalate as an intermediate step in the preparation of $\mathrm{PuO}_{2}$. Published solubility data (Burney and Porter 1967) show that a single oxalate precipitation step will not reduce TRU element concentrations to NRC Class $C$ waste levels let alone to the Class $A$ waste level. However, coprecipitation with other insoluble oxalates (e.g., La, Ca) might allow these levels to be achieved.

Trivalent lanthanide fluorides are insoluble in dilute $\mathrm{HNO}_{3}$ media. Advantage of this property has been taken in devising analytical scale coprecipitation of TRU elements in their +3 and +4 oxidation states. This coprecipitation technique typically reduces TRU element concentrations by a factor of $10^{2}$ to $10^{3}$. Concentrations of rare earth elements which are only 
slightly in excess of the stoichiometric fluoride ion concentration form crystals which are about $4 \times 10^{-7} \mathrm{~m}$ in diameter; a quantitative separation of these small crystals from associated mother liquor is very difficult.

\subsubsection{Strontium}

Strontium in alkaline solutions is precipitated by carbonate ions and under certain conditions, hydroxide. In weakly acidic solutions $\mathrm{Sr}^{2+}$ can be precipitated by addition of sulfate ions. In plant-scale operations at the DOE Hanford site megacuries of ${ }^{90} \mathrm{Sr}$ in the acidic raffinate from PUREX process operations were removed by coprecipitation on rare earth sulfates. Rare earth and ${ }^{90} \mathrm{Sr}$ sulfates were precipitated by addition of sodium sulfate and a rare earth nitrate solution to the waste which had previously been adjusted to $\mathrm{pH}$ 1-2. The rare earth $-{ }^{90} \mathrm{Sr}$ sulfate precipitate was digested, centrifuged, and treated with sodium carbonate solution to metathesize sulfates to carbonates. Hydroxide metathesis was not performed because of the solubility of strontium hydroxide in this waste. After washing, the carbonate solids were dissolved in $\mathrm{HNO}_{3}$ to prepare a suitable feed for further ${ }^{90} \mathrm{Sr}$ recovery and purification operations.

All candidate strontium precipitates are fairly soluble. In consequence, none of these precipitation schemes are capable, in a singie precipitation step, of removing more than about $90 \%$ of the ${ }^{90} \mathrm{Sr}$ in a waste stream. When applied to acidifed ICPP calcine, another major disadvantage to use of precipitation technology to remove ${ }^{90} \mathrm{Sr}$ is that large amounts of calcium in the waste solution would also precipitate with the ${ }^{90} \mathrm{Sr}$.

\subsubsection{Cesium}

A whole host of precipitation and/or coprecipitation processes for removal of ${ }^{137} \mathrm{Cs}$ from both acidic and alkaline solutions are known. Several of these processes have either been used on a plant-scale or are actively being developed for such use. For example, addition of PTA (phosphotungstic acid) to acidic ( $-1 \mathrm{M} \mathrm{HNO}_{3}$ ) waste solutions was used at the DOE Hanford site for several years to remove and recover megacuries of ${ }^{137} \mathrm{Cs}$. A cesium tetraphenylborate (TPB) precipitation process has been developed and tested 
for plant-scale use for removal of ${ }^{137} \mathrm{Cs}$ from large volumes of alkaline waste stored at the DOE Savarinah River site. In this process, potassium TPB also precipitates, acting as a carrier, to give the desired Cs decontamination factor in a single step.

Other acid-side ${ }^{137} \mathrm{Cs}$ precipitates include ammonium phosphomolybdate and ammonium phosphotungstate. Precipitation of metal, e.g., Ni(II), Co(II), $\mathrm{Zn}(\mathrm{II})$, etc. ferrocyanides at $\mathrm{pH} 9-10$ is a highly effective way of removing ${ }^{137} \mathrm{Cs}$ from alkaline waste solutions. Large-scale nickel ferrocyanide scavenging of ${ }^{137} \mathrm{Cs}$ from aged $\mathrm{BiPO}_{4}$ process alkaline wastes was performed at the DOE Hanford site in the period 1954 to 1957.

Safety concerns are often associated with the use of either nickel ferrocyanide or TPB precipitation of ${ }^{137} \mathrm{Cs}$ from aqueous waste solutions. Dry mixtures of nickel ferrocyanide and nitrite or nitrate salts may undergo rapid exothermic reaction when heated above about $240{ }^{\circ} \mathrm{C}$. Safety concerns involved with TPB precipitation of ${ }^{137} \mathrm{Cs}$ arise during subsequent hydrolytic treatment of the TPB precipitate to release, stepwise, the four benzene groups. In addition, radiolysis decomposes TPB releasing benzene to process solutions and overhead gases in all process steps. Because of its toxic nature, special pains must be taken to prevent personnel exposure to benzene and to ensure that no benzene is released to the environment.

A disadvantage of most cesium precipitation or co-precipitation processes is that adequate removal of ${ }^{137} \mathrm{Cs}$ cannot be realized in a single precipitation. Attainment of required decontamination from ${ }^{137} \mathrm{Cs}$ requires either performance of several precipitation steps or coupling of a single stage of precipitation with another tailend process such as ion exchange.

Radioactive cesium in the ICPP calcine is diluted with nonradioactive cesium also formed in the fission process. Further isotopic dilution of the ${ }^{137} \mathrm{Cs}$ in the dissolved calcine would likely increase the amount of radioactive cesium removed in the first and any succeeding precipitation steps. 


\subsubsection{Technetium}

In both alkaline and acidic media ${ }^{99} \mathrm{Tc}$ exists in the stable +7 oxidation state. Liquid-liquid extraction and ion exchange technology are generally preferred over other methodology for removal of ${ }^{99} \mathrm{Tc}$ from such solutions. Precipitation of copper and rhenium sulfides from certain solutions is known to coprecipitate ${ }^{99} \mathrm{Tc}$. Much additional work is needed to optimize conditions for precipitation of technetium sulfide.

\subsubsection{Iodine}

Palladium iodide $\left(\mathrm{PdI}_{2}\right)$ is a very insoluble compound. Precipitation of $\mathrm{PdI}_{2}$ has been proposed and studied as a way of removing ${ }^{129} \mathrm{I}$ and other iodine isotopes from the solution obtained by dissolving irradiated commercial 1 ight water reactor fuel in $\mathrm{HNO}_{3}$. Precipitation of $\mathrm{PdI}_{2}$ may be a suitable way of removing radioiodine from acidified ICPP calcine. To ensure sufficient removal of ${ }^{129} \mathrm{I}$ all iodine species in the calcine dissolver solution would need to be reduced to iodide ion by addition of a suitable reductant, e.g., HAN (hydroxylamine nitrate). Addition of a nonradioactive iodide carrier to the dissolver solution would also likely be necessary to achieve required removal of the radioactive iodine. 


\subsection{APPLICATION OF SEPARATIONS TECHNOLOGY TO ICPP CALCINE}

\subsection{INTRODUCTION}

The principal thrust of Section 4.0 of this report is three-fold:

- To discuss technology development efforts required to (1) more completely characterize ICPP calcine; (2) establish procedures for aqueous dissolution of various kinds of calcine; and (3) to establish stability of calcine dissolver solutions to precipitation of solids.

- To describe the methodology followed to choose and rank the various technologies described in Section 3.0 for their perceived applicability to aqueous solutions of ICPP calcine.

- To list and discuss the results of the technology selection process.

\subsection{CHARACTERIZATION OF ICPP CALCINE}

Preliminary characterization data for the ICPP calcine are provided in Berreth (1988). Additional and more detailed characterization data is needed, however, to develop and demonstrate integrated process flowsheets for producing a low-level waste meeting NRC Class A waste specifications. A program to sample and analyze all the various types of calcine needs to be developed and implemented. Quantitative data for the presence and amount of four classes of analytes need to be assembled with the following priorities:

- Priority 1: ${ }^{90} \mathrm{Sr},{ }^{99} \mathrm{TC},{ }^{129} \mathrm{I},{ }^{137} \mathrm{Cs},{ }^{237} \mathrm{~Np},{ }^{239} \mathrm{Pu}$

${ }^{241} \mathrm{Am}$

- Priority 2: ${ }^{14} \mathrm{C},{ }^{63} \mathrm{Ni}$

- Priority 3: Hazardous metals including $\mathrm{Cd}, \mathrm{Cr}, \mathrm{Hg}$, and $\mathrm{Pb}$

- Priority 4: Other non-radioactive constituents 


\subsection{DISSOLUTION OF ICPP CALCINE}

\subsubsection{Water Leaching}

Water leachability is of interest here because early removal of the dominant radionuclides $\left({ }^{137} \mathrm{CS}\right.$ and $\left.{ }^{90} \mathrm{Sr}\right)$ may greatly reduce the shielding requirements in subsequent processing operations. Some experimental data concerning water leaching of actual ICPP calcine are available (McLain and Rhodes 1958; Paige 1966; Wilding and Rhodes 1969; Staples, Paige, and Rhodes 1982). These data show that simple water leaching will dissolve 15 to $20 \mathrm{wt} \%$ of calcine which contains significant concentrations of alkali metals, nitrate ion, or elements such as boron and aluminum. Currently available data (McLain and Rhodes 1958; Wilding and Rhodes 1969) also indicate that almost all the ${ }^{137} \mathrm{CS}$ and up to $50 \%$ of the ${ }^{90} \mathrm{Sr}$ can be removed from at least some ICPP calcine by simple water washing. Water leachability of other radionuclides has not been established.

\subsubsection{Acid Dissolution}

Preliminary data from tests with actual ICPP calcines indicate they dissolve fairly rapidly in $\mathrm{HNO}_{3}$ or $\mathrm{HNO}_{3}$ - $\mathrm{HF}$ solutions. For example, 95 to $99 \%$ of an actual $\mathrm{Zr}$-based calcine dissolved in 6-8 $\mathrm{M} \mathrm{HNO}_{3}$ at $90-95{ }^{\circ} \mathrm{C}$ (Butler and Tramme11 1977; Butler and Tramme11 1978). From 98 to $99 \%$ of this type of calcine dissolved when the $\mathrm{HNO}_{3}$ dissolvent contained a small concentration of $\mathrm{HF}$. In similar experiments with actual Al-based calcine, almost all the calcine sample dissolved in 2 to $8 \mathrm{M} \mathrm{HNO}_{3}$ at $25{ }^{\circ} \mathrm{C}$ (Paige 1966).

\subsubsection{Systematic Calcine Leach/Dissolution Studies}

Systematic studies with all the different types of ICPP calcine should be performed to establish optimum conditions for both water leaching and acid dissolution of the water-washed calcine. Important experimental parameters to be studied in such tests include: 


\section{Water Leaching}

Temperature

Contact Time

Number of Leaches

Solid-to-Liquid Ratio

Calcine Particle Size

Type of Agitation

Degree of Agitation

\section{Acid Dissolution}

Dissolvent Composition

$\mathrm{HNO}_{3}$ Concentration

Complexant concentration (e.g., fluoride or oxalate)

Temperature

Contact Time

Solid-to-Liquid Ratio

Calcine Particle Size

Type of Agitation

Degree of Agitation

Number of Dissolution Cycles

Initially, appropriate statistically-designed screening tests should be performed to establish those leaching and dissolution variables of greatest importance. For these tests, it is probably only necessary to determine the amount of ${ }^{137} \mathrm{CS}$ solubilized during each water leaching test and the amount, mass and volume, of calcine not dissolved in each acid dissolution test. Note that it may be necessary or desirable to conduct acid dissolution tests with both as-retrieved and with retrieved, then water-leached calcine.

Results of the preliminary leaching and acid dissolution tests will guide selection of experimental criteria for defining optimum water leaching and/or acid dissolution conditions for each type of ICPP calcine. In later, more comprehensive, tests, water leachates should be analyzed to determine the amounts of all important solubilized components, both radioactive and nonradioactive. Insoluble residues need to be characterized to determine their mass and composition. An important goal of the comprehensive leaching and dissolution tests is to establish recommended procedures for pilot plant-scale tests.

\subsection{STABILITY OF ACIDIC CALCINE DISSOLVER SOLUTIONS}

The acid solution resulting from dissolution of ICPP calcine will constitute feed for subsequent chemical separations processes, see Section 5.0. To achieve required removal of various radionuclides of importance and to ensure trouble-free operation of separations process equipment, it is essential that the acidic dissolver solutions be suitably stable toward precipitation of solids. Solids which precipitate from the acidic feed solution could carry down TRU elements and/or ${ }^{90} \mathrm{Sr}$ and could also 
lead to phase disengaging problems in liquid-liquid extraction process equipment.

An experimental program should be designed and implemented to investigate and establish the stability towards solids formation of dissolver solutions prepared from various types of ICPP calcine. Important variables to study, perhaps in statistically-designed experiments, are:

- $\mathrm{HNO}_{3}$ Concentration

- Total Fluoride Concentration

- Uncomplexed HF Concentration

- Concentrations of $\operatorname{Zr(IV)}$ and AI(III)

- Time

- Temperature

In each test, the precipitation of any solids should be noted along with a qualitative estimate of their volume or mass; dissolvability of any precipitated solids should be determined. In some cases, it may be necessary or desirable to analyze precipitated solids to establish their content of radionuclides and inert components.

\subsection{EVALUATION AND RANKING OF CANDIDATE SEPARATIONS PROCESSES AND TECHNOLOGY}

\subsubsection{Introduction}

The information and discussions in Section 3.0 of this report provided the Panel sufficient basis to select generic separations technology options and specific processes and/or reagents for application to dissolved ICPP calcine. For each radionuclide of interest, e.g., TRU elements, ${ }^{90} \mathrm{Sr},{ }^{99} \mathrm{Tc}$, ${ }^{129} \mathrm{I}$, and ${ }^{137} \mathrm{Cs}$, each Fanel member ranked (i.e., 1st, 2nd, etc.) generic and specific technologies according to individual judgements of how well a particular technology could be applied to dissolved ICPP calcine. Points were assigned to each ranking according to the schedule: 
First - 4 points

Second - 3 points

Third - 2 points

Fourth - 1 point

The point total for each generic separations technology was calculated and tabulated; these point totals correspond to those technologies believed most applicable to ICPP calcine and to those technologies and processes where further development efforts should be focussed.

\subsubsection{Transuranium Elements}

Table 4.1 lists the generic separations technology and specific reagents or processes evaluated for removal of TRU elements from dissolved ICPP calcine. Results of the Panel's evaluation and ranking are shown in Table 4.2.

The Panel believes that a liquid-liquid extraction process utilizing a bifunctional reagent such as CMPO (TRUEX process) or DHDECMP is the most promising technology for separation of actinides elements from acidified ICPP calcine. Continuous countercurrent solvent extraction processes are, of course, extremely adaptable to remote operation of nuclear separations processes. Bifunctional compounds are powerful extractants for TRU elements from strongly acidic solutions and will also extract ${ }^{99} \mathrm{TC}$ (as $\mathrm{HTCO}_{4}$ ) from acid feed solutions. Of course, close attention must be given to careful use of masking agents such as oxalic acid to minimize extraction of contaminants such as $\operatorname{Zr}$ (IV) and $\mathrm{Fe}$ (III).

of the other technologies for TRU element removal, the Panel believes that extraction chromatographic procedures using EIChrom Industries TRU.Spec resin may have some advantages for removal of TRU elements from acidified ICPP calcine. Some experimental work to investigate application of extraction chromatography appears warranted. Conversely, the Panel believes that other technologies, i.e., ion exchange and precipitation, are not particularly applicable to selectively removal of TRU elements from $\mathrm{HNO}_{3}$ solutions of ICPP calcine. 
TABLE 4.1 CANDIDATE TRU ELEMENT REMOVAL TECHNOLOGIES

\begin{tabular}{|c|c|c|c|}
\hline \multicolumn{2}{|r|}{ Technology } & Reagents & Comments \\
\hline & $S X^{(a)}$ & CMPO, DHDECMP, Diamides & $\begin{array}{l}\text { TRUEX process technology is } \\
\text { most advanced and mature. }\end{array}$ \\
\hline & $I X_{\text {inoro }}$ & CST, sodium titanates & $\begin{array}{l}\text { Sodium titanate sorption } \\
\text { efficiency decreases in low } \\
\text { pH solutions; CST shows } \\
\text { excellent potential if } \\
\text { sorption of main inert } \\
\text { species (e.g., Zr, Al) is } \\
\text { not too severe. }\end{array}$ \\
\hline & IX $X_{\text {organic }}$ & Cation resins & $\begin{array}{l}\text { Cation exchange resins } \\
\text { exhibit low selectivity in } \\
\text { multi-component systems. }\end{array}$ \\
\hline & $E C$ & $\begin{array}{l}\text { EIChrom Industries } \\
\text { TRU.Spec sorbent }\end{array}$ & $\begin{array}{l}\text { Promising bench-scale } \\
\text { technology needs to be } \\
\text { demonstrated on a } \\
\text { plant-scale. Loading by } \\
\text { inert species could be a } \\
\text { problem. }\end{array}$ \\
\hline & PPT & $\begin{array}{l}\text { Oxalate, fluoride } \\
\text { phosphate }\end{array}$ & $\begin{array}{l}\text { Batch processes; potential } \\
\text { poor TRU element removal; } \\
\text { possible precipitation of } \\
\text { contaminants. }\end{array}$ \\
\hline (a) & \multicolumn{3}{|c|}{ Definition of Acronyms: } \\
\hline & \multicolumn{3}{|c|}{$\begin{array}{l}\text { SX - Solvent Extraction } \\
\text { IX } X_{\text {inoro }} \text { Ion Exchange, inorganic materials } \\
\text { IX }{ }_{\text {organic }} \\
\text { EC - Ion Exchange, organic materials } \\
\text { PPT - Precipitation and/or Coprecipitation }\end{array}$} \\
\hline
\end{tabular}

TABLE 4.2 RANKING OF CANDIDATE TRU ELEMENT SEPARATIONS TECHNOLOGIES

\begin{tabular}{|c|c|c|c|c|c|}
\hline \multirow[b]{2}{*}{ Rank } & \multicolumn{5}{|c|}{ Number of Votes } \\
\hline & SX & IX $X_{\text {inora }}$ & IX $X_{\text {ornenta }}$ & $E C$ & PPT \\
\hline FIRST & 6 & & & & \\
\hline SECOND & & & & 5 & 1 \\
\hline THIRD & & & 6 & & \\
\hline FOURTH & & & & 1 & 5 \\
\hline TOTAL POINTS & 24 & 0 & 12 & 16 & 8 \\
\hline
\end{tabular}




\subsubsection{Strontium}

Table 4.3 lists the generic separations technologies and specific reagents or processes evaluated for removal of ${ }^{90} \mathrm{Sr}$ from acidified ICPP calcine. Results of the Panel's ranking are shown in Table 4.4.

In the Panel's opinion, the SREX process, a liquid-liquid extraction process employing a crown ether as the extractant, is currently the favored technology for removal of ${ }^{90} \mathrm{~S} r$ from dissolved calcine. Considerable bench-scale testing of the SREX process has been accomplished, and more is planned or in progress at several DOE sites. The SREX process is also attractive because the crown ether extractant is highly selective for ${ }^{90} \mathrm{Sr}$ over calcium, and because it will also extract $\mathrm{H}^{99} \mathrm{TCO}_{4}$ efficiently from acidic medium.

The cobalt dicarbollide extraction process being developed and tested by Russian and Czechoslovakian scientists may also eventually be useful for combined removal of ${ }^{90} \mathrm{Sr}$ and ${ }^{137} \mathrm{Cs}$ from acidified ICPP calcine. As pointed out previously, currently known diluents for cobalt dicarbollide are all considered highly toxic chemicals in the US. Another possible disadvantage of the dicarbollide extraction process is that ${ }^{90} \mathrm{Sr}$ and ${ }^{137} \mathrm{Cs}$ extraction can only be performed efficiently over a relatively narrow range, e. g., 0.5 to 1 or 2 $\mathrm{MHNO}_{3}$, of feed acidities.

The Panel believes (Table 4.4) that precipitation processes and organic ion exchange resins have little or no merit for plant-scale removal of ${ }^{90} \mathrm{Sr}$ from dissolved calcine. With further development, certain inorganic sorbents, e.g., CST, may prove useful for selective and efficient removal of ${ }^{90} \mathrm{Sr}$ from acidic waste solutions. Similarly, extraction chromatographic materials such as the EIChrom Industries product Sr.Spec may eventually be found, after much more testing, to be useful for plant-scale removal of ${ }^{90} \mathrm{Sr}$ from acidic media. The Panel recommends that WINCO scientists/engineers closely track progress of further development and testing of CST, Sr.Spec, and cobalt dicarbollide materials and processes. 
TABLE 4.3 CANDIDATE STRONTIUM REMOVAL TECHNOLOGIES

\begin{tabular}{|c|c|c|}
\hline Technology & Reagents & Comments \\
\hline$s x$ & $\begin{array}{l}\text { Crown ethers } \\
\text { Cobalt dicarbollide }\end{array}$ & $\begin{array}{l}\text { Crown ether (SREX) process is } \\
\text { advanced and mature; no } \\
\text { acceptable nontoxic diluent for } \\
\text { cobalt dicarbollide is } \\
\text { currently identified. }\end{array}$ \\
\hline I $X_{\text {inore }}$ & $\begin{array}{l}\text { Antimonic Acid } \\
\text { CST } \\
\text { Sodium titanate }\end{array}$ & $\begin{array}{l}\text { Antimonic acid sorbs }{ }^{90} \mathrm{Sr} \text { from } \\
\text { highly acidic media but no } \\
\text { simple eluent is known; sodium } \\
\text { titanate sorption efficiency } \\
\text { decreases in low pH solution; } \\
\text { CST shows excellent potential } \\
\text { but needs further development. }\end{array}$ \\
\hline$I X_{\text {organic }}$ & Cation Resins & $\begin{array}{l}\text { Cation exchange resins exhibit } \\
\text { low selectivity in } \\
\text { multicomponent systems. }\end{array}$ \\
\hline$E C$ & $\begin{array}{l}\text { EIChrom Industries } \\
\text { Sr.Spec resin }\end{array}$ & $\begin{array}{l}\text { Excellent results in analytical } \\
\text { applications; technology not } \\
\text { demonstrated for plant-scale } \\
\text { applications }\end{array}$ \\
\hline PPT & $\begin{array}{l}\text { Rare Earth and Lead } \\
\text { Sulfates }\end{array}$ & $\begin{array}{l}\text { Batch processes; potential for } \\
\text { removal of } 90 \mathrm{Sr} \text { in single } \\
\text { precipitation is poor; likely } \\
\text { precipitation of contaminants }\end{array}$ \\
\hline
\end{tabular}

TABLE 4.4 RANKING OF CANDIDATE STRONTIUN SEPARATION TECHNOLOGIES

\begin{tabular}{|c|c|c|c|c|c|}
\hline \multirow[b]{2}{*}{ Rank } & \multicolumn{5}{|c|}{ Number of Votes } \\
\hline & $s x$ & $I X_{\text {inore }}$ & IX $X_{\text {organio }}$ & EC & PPT \\
\hline FIRST & 4 & 2 & & & \\
\hline SECOND & 2 & 1 & & & 3 \\
\hline THIRD & & 3 & & & 3 \\
\hline \multicolumn{6}{|l|}{ FOURTH ${ }^{(a)}$} \\
\hline TOTAL POINTS & 22 & 17 & & & 15 \\
\hline (a) No fourt & ices & by any & member & & \\
\hline
\end{tabular}




\subsubsection{Technetium}

Table 4-5 lists the generic separations technologies and specific reagents or processes evaluated for removal of ${ }^{99}$ TC from acidified ICPP calcine. Results of the Panel's ranking of these technologies are presented in Table 4-6.

From available published data, it appears preferable to remove ${ }^{99} \mathrm{Tc}$ during extraction of TRU elements and/or ${ }^{90} \mathrm{Sr}$. Any of the extractants CMPO, DHDECMP, or crown ether should provide entirely suitable extraction of ${ }^{99} \mathrm{Tc}$.

Anion exchange resins can also be applied to removal of ${ }^{99} \mathrm{Tc}$ from acidified calcine either before or, preferably, after removal of TRU elements and ${ }^{90} \mathrm{Sr}$. For the anion exchange resin process, the feed acidity needs to be fairly low (<0.5 $\mathrm{M} \mathrm{HNO}_{3}$ ) while sorbed ${ }^{99} \mathrm{Tc}$ can only be eluted with strong, e.g., 3-6 M, $\mathrm{HNO}_{3}$ solutions.

Chromatographic and precipitation processes do not appear to be particularly suitable for removal of technetium from acidified ICPP calcine.

\subsubsection{Cesium}

Table 4-7 1ists the generic separations technologies and specific reagents or processes evaluated for removal of ${ }^{137} \mathrm{Cs}$ from acidified ICPP calcine. Results of the Panel's ranking of these technologies are presented in Table 4.8 .

The Panel believes that both acid-side and alkaline-side processes for removal of ${ }^{137} \mathrm{Cs}$ from solutions of ICPP calcine should be considered and investigated. Thus, further evaluations may show that it is both economically and technically desirable to make acidified calcine solutions, after prior removal of TRU elements, ${ }^{90} \mathrm{Sr},{ }^{99} \mathrm{Tc}$, and ${ }^{129} \mathrm{I}$, alkal ine and remove ${ }^{137} \mathrm{Cs}$ from the alkaline supernatant liquid. 
TABLE 4-5 CANDIDATE TECHNETIUM REMOVAL TECHNOLOGIES

\begin{tabular}{|c|c|c|}
\hline Technology & Reagents & Comments \\
\hline SX & $\begin{array}{l}\text { DHDECMP, CMPO, Crown } \\
\text { ethers, amines, TBP }\end{array}$ & $\begin{array}{l}\text { CMPO and certain crown ethers } \\
\text { are known to efficiently extract } \\
{ }^{99} \mathrm{Tc} \text { from } \mathrm{HNO}_{3} \text { solutions; } \\
\text { certain tertiary amines and } \\
\text { quaternary ammonium compounds } \\
\text { readily extract }{ }^{99} \mathrm{Tc} \text { from } 1-3 \mathrm{M} \\
\mathrm{HNO}_{3} \text { media; DHDECMP and } \mathrm{TBP}^{-} \\
\text {solutions extract }{ }^{99} \mathrm{TC} \text { from } \mathrm{HNO}_{3} \\
\text { media but are less powerful } \\
\text { extractants than are CMPO, crown } \\
\text { ethers, and amines. }\end{array}$ \\
\hline IX $X_{\text {organic }}$ & $\begin{array}{l}\text { Strongly and weakly basic } \\
\text { anion exchange resins }\end{array}$ & $\begin{array}{l}\text { Excellent selectivity and } \\
\text { capacity for }{ }^{99} \mathrm{Tc} \text { from alkaline } \\
\text { and weakly acid solutions; } \\
\text { strong, i. e., > } 3 \mathrm{M} \mathrm{HNO}_{3} \text {, acid } \\
\text { solutions are needed to elute } \\
\text { technetium; Pd and Rh species } \\
\text { cosorb with Tc. }\end{array}$ \\
\hline$E C$ & $\begin{array}{l}\text { EIChrom Industries TRU. } \\
\text { and Sr.Spec resins. }\end{array}$ & $\begin{array}{l}\text { Technetium known to sorb but } \\
\text { very little bench-scale data are } \\
\text { available. }\end{array}$ \\
\hline PPT & CuS, RhS & $\begin{array}{l}\text { Very little experimental data } \\
\text { are available }\end{array}$ \\
\hline
\end{tabular}

TABLE 4-6 RANKING OF CANDIDATE TECHNETIUM REMOVAL TECHNOLOGIES

\begin{tabular}{|c|c|c|c|c|c|}
\hline \multirow[b]{2}{*}{ Rank } & \multicolumn{5}{|c|}{ Number of Votes } \\
\hline & sx & $1 X_{\text {imorg }}$ & $I X_{\text {organio }}$ & EC & PPT \\
\hline FIRST & 6 & & & & \\
\hline SECOND & & & 6 & & \\
\hline THIRD & & & & 6 & \\
\hline FOURTH & & & & & 6 \\
\hline TOTAL POINTS & 24 & & 18 & 12 & 6 \\
\hline
\end{tabular}


TABLE 4-7 CANDIDATE TECHNOLOGIES FOR REMOVAL OF CESIUM

\begin{tabular}{|c|c|c|}
\hline Technology & Reagents & Comments \\
\hline SX Acid & $\begin{array}{l}\text { Crown ethers, cobalt } \\
\text { dicarbollide }\end{array}$ & $\begin{array}{l}\text { Solvent extraction process } \\
\text { technology for Cs removal is not } \\
\text { fully developed. Currently } \\
\text { available data support crown } \\
\text { ether process over cobalt } \\
\text { dicarbollide process. No } \\
\text { acceptable diluent for cobalt } \\
\text { dicarbollide identified. }\end{array}$ \\
\hline$I X_{\text {inoro }}$ Acid & Zeolites, $\operatorname{CST}^{(a)}$ & $\begin{array}{l}\text { Zeolites sorb }{ }^{137} \mathrm{CS} \text { from weakly } \\
\text { acid solutions; CST may be } \\
\text { useful for } 1 \mathrm{M} \mathrm{HNO}_{3} \text { feeds. CST } \\
\text { technology not fully developed; } \\
\text { suitable eluent for sorbed } \\
\text { cesium not identified. Other } \\
\text { inorganic sorbents are less } \\
\text { attractive than are zeolites and } \\
\text { CST. }\end{array}$ \\
\hline$I_{\text {organic }} A 1 \mathrm{kal}$ ine & $\begin{array}{l}\text { Phenolic- and } \\
\text { resorcinol-based cation } \\
\text { exchange resins }\end{array}$ & $\begin{array}{l}\text { Phenolic-based resins widely } \\
\text { used and applied, } \\
\text { resorcinol-based resins are more } \\
\text { selective and have more capacity } \\
\text { for cesium, but are not fully } \\
\text { developed and tested. }\end{array}$ \\
\hline EC Acid & $\begin{array}{l}\text { No completely reliable } \\
\text { reagent identified (b) }\end{array}$ & $\begin{array}{l}\text { Not applicable, at this stage of } \\
\text { development, to removal of }{ }^{137} \mathrm{Cs} \\
\text { from ICPP calcine. }\end{array}$ \\
\hline PPT Acid & $\begin{array}{l}\text { Phosphotungstic acid, } \\
\text { phosphomolybdic acid }\end{array}$ & $\begin{array}{l}\text { PTA used on plant-scale at DOE } \\
\text { Hanford site; single } \\
\text { precipitation of CSPTA only } \\
\text { removes } 95 \text { to } 98 \% \text { of }{ }^{137} \mathrm{Cs} \text {. }\end{array}$ \\
\hline PPT Alkal ine & $\begin{array}{l}\text { Tetraphenyl-boron, metal } \\
\text { ferrocyanides }\end{array}$ & $\begin{array}{l}\text { Safety concerns about use of } \\
\text { ferrocyanides exist. Safety } \\
\text { concerns and process problems in } \\
\text { destruction of benzene portion } \\
\text { of TPB exist. }\end{array}$ \\
\hline \multicolumn{3}{|c|}{$\begin{array}{l}\text { Other possibilities include titanium phosphate, zirconium phosphate, } \\
\text { metal ferrocyanides, ammonium phosphotungstate, and ammonium } \\
\text { phosphomolybdate. } \\
\text { Crown ethers, sorbed on or bonded to an inert substrate, e.g., silica } \\
\text { gel (so-called Molecular Recognition Technology) may be a suitable } \\
\text { material. }\end{array}$} \\
\hline
\end{tabular}


TABLE 4-8 RANKING OF CANDIDATE CESIUM REMOVAL TECHNOLOGIES Number of Votes

$\begin{array}{lllll}\text { Rank } & \text { SX } I X_{\text {inorg }} & I X_{\text {organic }} & \text { EC } & \text { PPT }\end{array}$

\section{ACIDIC MEDIA}

\begin{tabular}{|c|c|c|c|c|c|}
\hline FIRST & 1 & 2 & & & 3 \\
\hline SECOND & 3 & 1 & & & 2 \\
\hline THIRD & 2 & 2 & & & 1 \\
\hline FOURTH & & & & 4 & \\
\hline TOTAL POINTS & 17 & 15 & & 4 & 20 \\
\hline \multicolumn{6}{|c|}{ ALKALINE MEDIA } \\
\hline FIRST & & 2.5 & 3.5 & & \\
\hline SECOND & 3 & 2 & 1 & & \\
\hline FHIRD & 1 & & 1 & & 4 \\
\hline FOURTH & 2 & 1 & & 1 & 2 \\
\hline TOTAL POINTS & 13 & 17 & 19 & 1 & 10 \\
\hline
\end{tabular}

From acidic calcine solutions, solvent extraction, precipitation, and inorganic ion exchange technology all appear to be equally applicable. Precipitation of cesium phosphotungstate was successfully practiced on a plant-scale for several years at the DOE Hanford site. Very likely, two or more precipitations of cesium with phosphotungstic acid would be required to attain required removal of ${ }^{137} \mathrm{Cs}$. Liquid-liquid extraction of ${ }^{137} \mathrm{Cs}$ from acidic media would be a very satisfactory way of removing radiocesium from acidified ICPP calcine provided either or both cobalt dicarbollide or crown ether processes can be successfully developed and demonstrated. Zeolites and CST exchangers may also be useful in removal of ${ }^{137} \mathrm{Cs}$. Coupling of a precipitation step with a tailend sorption process also should be considered for removal of ${ }^{137} \mathrm{Cs}$ from acidified ICPP calcine.

The Panel favors uses of well-established ion exchange, either organic or inorganic sorbents, process technology for removal of ${ }^{137} \mathrm{Cs}$ from alkaline solutions which would be generated in partitioning of radionuclides from dissolved ICPP calcine. Phenolic-based cation exchange resins are the industry standard for effective removal of ${ }^{137} \mathrm{Cs}$ from alkaline solutions. Newer, resorcinol-based cation exchangers also appear to be highly selective 
for ${ }^{137} \mathrm{Cs}$ and may eventually supplant the phenolic-based resin. The Panel recommends that both types of organic ion exchangers be examined in bench-scale tests with actual dissolved ICPP calcine. Such bench-scale tests should also include studies of the application of the inorganic ion exchangers CST and zeolites to removal of ${ }^{137} \mathrm{Cs}$ from ICPP calcine solutions which have been made alkaline.

The Panel also recommends that progress in various world-wide laboratories toward development and demonstration of solvent extraction processes employing either crown ethers or cobalt dicarbollide be closely monitored. Such processes may have significant advantages for removal of ${ }^{137} \mathrm{Cs}$ from either acidic or alkaline ICPP calcine solutions. Finally, the Panel notes that several precipitation processes, e.g., nickel ferrocyanide and cesium tetraphenylborate, are also proven ways of removing ${ }^{137} \mathrm{Cs}$ from alkaline solutions; however, their application to ICPP calcine solutions would involve several safety concerns.

\subsubsection{Iodine}

Table 4-9 lists the generic separations technologies and specific reagents or processes evaluated for removal of ${ }^{129}$ I from acidified ICPP calcine. Results of the Panel's ranking of these technologies are presented in Table 4-10.

Volatilization of ${ }^{129}$ I during dissolution of the ICPP calcine would, in the Panel's opinion, be the most effective method for accomplishing needed removal of ${ }^{129} \mathrm{I}$. The Panel believes that iodine species present in the calcine can be reduced to $\mathrm{I}_{2}$ by including reagents such as sodium nitrite in the $\mathrm{HNO}_{3}$ solution used to dissolve the calcine. Sparging of the dissolver solution during and after the dissolution process should remove the ${ }^{129} \mathrm{I}$ which can then be trapped on a suitable sorber in the off gas system.

Alternatively, it may be possible and even desirable to remove ${ }^{129} \mathrm{I}$ during subsequent solvent extraction operation; to remove TRU elements and/or ${ }^{90} \mathrm{Sr}$. Again, iodine species would have to be reduced to molecular iodine; iodine then would report to the organic phase from which it could be removed 
TABLE 4-9 CANDIDATE IODINE REMOVAL TECHNOLOGIES

\begin{tabular}{|c|c|c|}
\hline Technology & Reagents & Comments \\
\hline$s x$ & DHDECMP, CMPO, TBP & $\begin{array}{l}\text { Reduce I species to } \mathrm{I}_{2} \text { with } \\
\text { sodium nitrite or HAN: extract } \\
\mathrm{I}_{2} \text { into solvent; remove } \mathrm{I}_{2} \text { by } \\
\text { alkaline washing or solvent. }\end{array}$ \\
\hline$V O L^{(a)}$ & Gas sparging & $\begin{array}{l}\text { Reduce I species to } I_{2} \text { by } \\
\text { addition of sodium nitrite or } \\
\text { HAN during dissolution of } \\
\text { calcine; sparge during } \\
\text { dissolution step; trap }{ }^{129} \text { I in } \\
\text { off gas sorber. }\end{array}$ \\
\hline PPT & $\mathrm{PdI}_{2}$ & $\begin{array}{l}\text { Palladium iodide is known to be } \\
\text { a very insoluble compound. }\end{array}$ \\
\hline 1) $V O L=V_{01}$ & lization & \\
\hline
\end{tabular}

TABLE 4-10 RANKING OF CANDIDATE IODINE REMOVAL TECHNOLOGIES

\begin{tabular}{|c|c|c|c|c|c|c|}
\hline \multirow[b]{2}{*}{ Rank } & \multicolumn{6}{|c|}{ Number of Votes } \\
\hline & $S X$ & $I X_{\text {inorg }}$ & IX $X_{\text {organic }}$ & $E C$ & PPT & VOL \\
\hline FIRST & & & & & & 6 \\
\hline SECOND & & & & & 6 & \\
\hline THIRD & 6 & & & & & \\
\hline FOURTH & & & & & & \\
\hline TOTAL POINTS & 12 & & & & 18 & 24 \\
\hline
\end{tabular}

by washing, after stripping of TRU elements and/or ${ }^{90} \mathrm{Sr}$, with an aqueous alkaline solution. For this reason, iodine precipitations should not be evaluated until its chemistry in the solvent extraction processes has been determined.

The Panel recommends that bench-scale studies of both the volatilization and solvent extraction approaches to removal of ${ }^{129} \mathrm{I}$ be pursued. Such studies should also address technology for final disposal of radioiodine trapped from dissolver off gas or in spent solvent washes. 


\subsection{POTENTIAL INTEGRATED RADIONUCLIDE PARTITIONING SCHEMES}

\subsection{INTRODUCTION}

Individual technologies considered in Sections 3.0 and 4.0 can be assembled into integrated radionuclide partitioning schemes in a variety of ways. Section 5.0 describes and discusses several such schemes which, in the opinion of the Panel, are those most worthy of initial consideration and study. Schemes considered include not only those which appear to have the greatest technical feasibility based upon current knowledge but also those which embrace process steps currently poorly understood and/or developed which offer potential process simplifications and advantages.

The goal of all the individual partitioning schemes presented and discussed in Section 4.0 is to produce a low-level waste which meets NRC Class A specifications for radionuclide content. Because of known environmental mobility, removal of ${ }^{129} \mathrm{I}$ and ${ }^{237} \mathrm{~Np}$ to concentration levels below Class $\mathrm{A}$ waste limits may be necessary and/or desirable. Exact radionuclide removal factors which are required/desired have not yet been defined but are thought to be of the order of $10^{6}$ for ${ }^{90} \mathrm{Sr}, 10^{4}$ for TRU elements and ${ }^{137} \mathrm{Cs}$, and $10^{2}$ for ${ }^{99} \mathrm{Tc}$ and ${ }^{129} \mathrm{I}$. Very likely, therefore, radionuclide partitioning schemes must provide for more than one cycle of ${ }^{90} \mathrm{Sr}$ removal. A single process cycle may be sufficient to accomplish required or desired removal of the other radionuclides.

All aqueous processing schemes involve dissolution of the retrieved calcine. As noted earlier, preliminary data indicate that heated aqueous $\mathrm{HNO}_{3}$ solutions containing, in some cases small amounts of fluoride ion, efficiently dissolve most of the calcine. By sparging during and after dissolution, a large fraction (about 99\%) of the ${ }^{129}$ I could be volatilized into the dissolver off gas, from which it could be removed by a suitable sorbent or scrub solution. Any undissolved solids must be removed to obtain a clarified feed for subsequent radionuclide separations operations. The undissolved solids can be: (1) returned to the primary dissolver for additional processing along with the next batch of calcine; (2) routed to a secondary dissolver for separation dissolution; or (3) if suitably low in volume/mass, combined with 
partitioned radionuclides for immobilization in an acceptable repository disposal form. The latter approach is shown in the generalized dissolution depiction shown in Figure 5.1. This routing of the undissolved calcine assumes that it is small enough in volume that it does not have an adverse impact on the HLW form volume.

The clarified dissolver solution from the calcine dissolution step will constitute feed to the mainline radio-chemical removal process. A feed adjustment step may be necessary depending upon conditions used to dissolve the calcine and upon the first separations process. For example, feed adjustment could involve adjustment of the oxidation state of ${ }^{237} \mathrm{~Np}$ to the extractable +4 or +6 state as well as addition of $\mathrm{HNO}_{3}$ and/or water.

\subsection{CONCEPTUAL PROCESSING SCHEMES}

\subsubsection{Scheme 1 (Figure 5-2.)}

The processing scheme shown in Figure 5-2 is considered to have the current highest technical feasibility. It involves:

- A liquid-liquid extraction process to remove TRU elements and, depending upon feed acidity, some ${ }^{99} \mathrm{~T} c$.

- A second liquid-liquid extraction process (SREX process) to remove ${ }^{90} \mathrm{Sr}$ and more ${ }^{99} \mathrm{TC}$.

- $A{ }^{137} \mathrm{Cs}$-removal process.

Two sequential ${ }^{90} \mathrm{Sr}$-removal cycles, with an intercycle treatment step, are believed necessary to provide the required high decontamination from ${ }^{90} \mathrm{Sr}$. Either CMPO or DHDECMP could likely be employed as the primary extractant in the TRU-element removal process; bench-scale and pilot plant-scale tests using simulated and actual dissolved ICPP calcine with both bifunctional extractants should be performed before choosing one over the other.

An important consideration in the process scheme shown in Figure 5-2 is the order of conducting TRU element and ${ }^{90} \mathrm{Sr}$ removal processing. Cross contamination of process solvents may engender some serious process 
Calcine

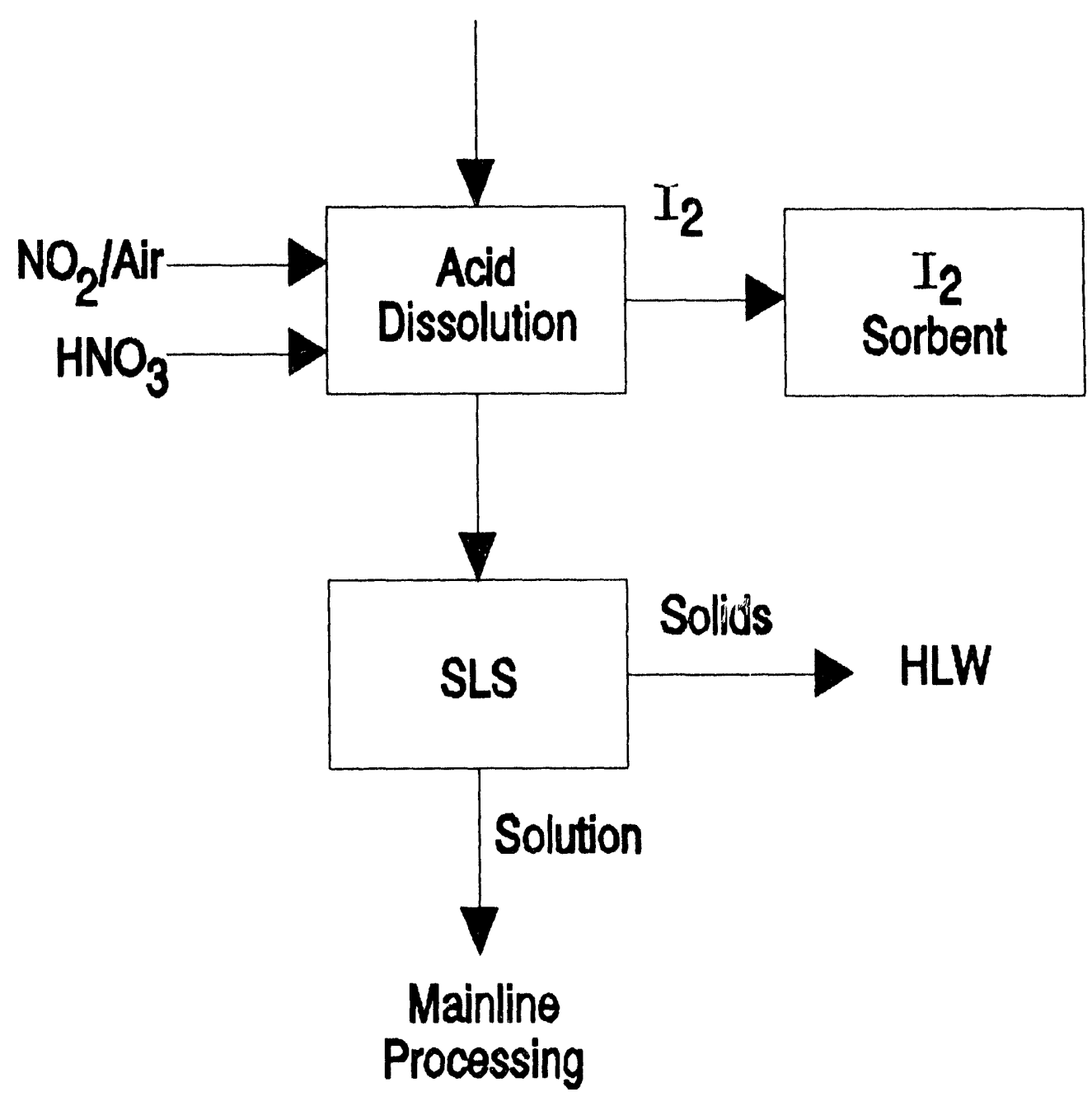

Figure 5-1. Calcine Dissolution and Iodine Removal 


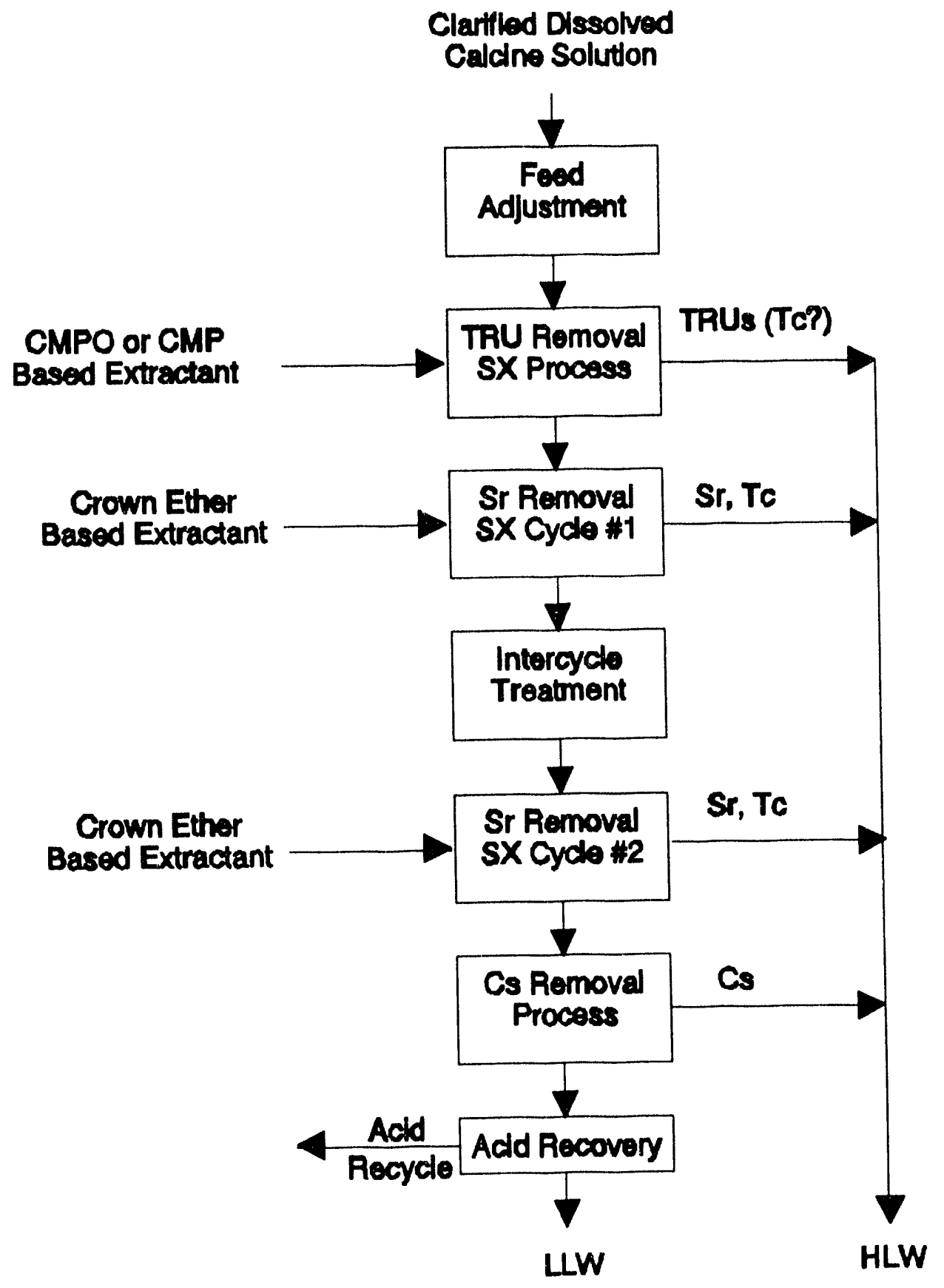

Figure 5-2. Radionuclide Removal in Separated Processes 
difficulties. For example, one candidate SREX process diluent, i.e., n-octanol, could have a deleterious effect on TRUEX process solvent performance. The process order specified in Figure 5-2 minimizes such effects. Also, of course, operation of both the SREX and TRU-element extraction processes with the same TBP-NPH diluent would also minimize solvent cross contamination problems.

\subsubsection{Scheme 2 (Fiqure 5-3)}

Figure 5-3 expands on the Cs-removal process step of Figure 5-2. The several approaches to removal of ${ }^{137} \mathrm{Cs}$ indicated in Figure 5-3 reflect the Panel's perception that there is no clear "winner" among the candidate technologies. Two of the approaches shown in Figure 5-3 involve removal of ${ }^{137} \mathrm{Cs}$ from acidic feed while one involves neutralization of the acidic feed, after removal of TRU elements, ${ }^{90} \mathrm{Sr}$, and ${ }^{99} \mathrm{Tc}$, to produce an alkaline liquor from which ${ }^{137} \mathrm{Cs}$ can be removed by well-known ion exchange process technology.

The behavior of zirconium in all the cesium removal schemes depicted in Figure 5-3 is of major concern and uncertainty. For example, hydrated zirconium oxide will precipitate when acidic feeds are neutralized; the zirconium precipitate will have to be washed free of ${ }^{137} \mathrm{Cs}$ to meet required decontamination factors, and this may be difficult to do. In the acid-side processes, some zirconium may accompany the ${ }^{137} \mathrm{Cs}$, thus decreasing both the efficiency of ${ }^{137} \mathrm{Cs}$ removal and the selectivity of the separations process. Behavior of zirconium is a key parameter to study early on in the experimental program.

\subsubsection{Scheme 3 (Figure 5-4)}

Figure 5-4 illustrates use of the so-called "combined process" to simultaneously extract TRU elements, ${ }^{90} \mathrm{Sr}$, and ${ }^{99} \mathrm{Tc}$ from the acid feed solution. In this case, the primary TRU element extractant (CMPO) and the primary ${ }^{90} \mathrm{Sr}$ and ${ }^{99} \mathrm{Tc}$ extractant (a crown ether) are combined in one solvent mixture along with a diluent (NPH) and a phase modifier (TBP). In the combined process, which has undergone a limited amount of successful testing at the Argonne National Laboratory, two rather than three extraction cycles 


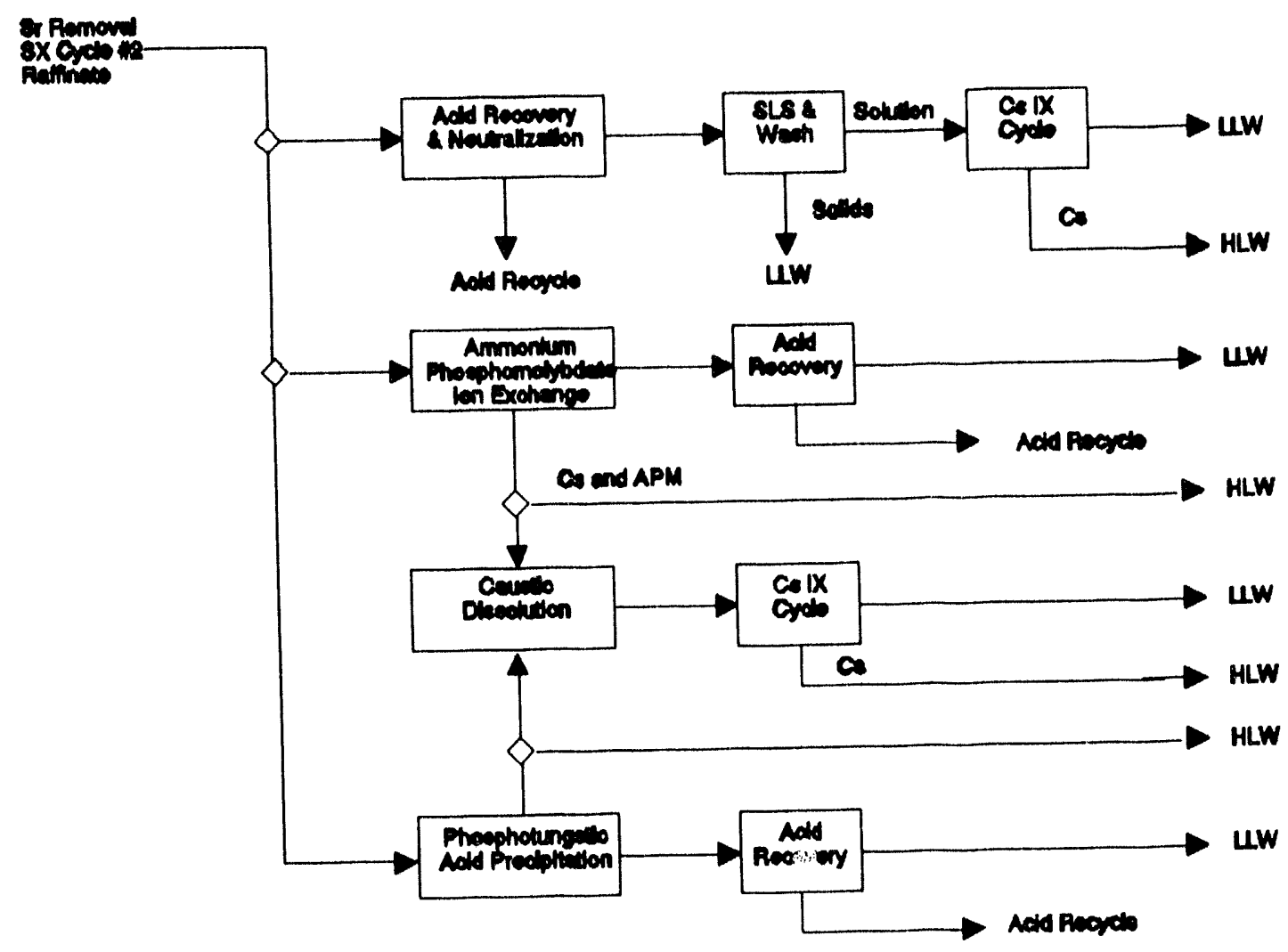

Figure 5-3. Some Promising ${ }^{137}$ Cs Removal Processes 


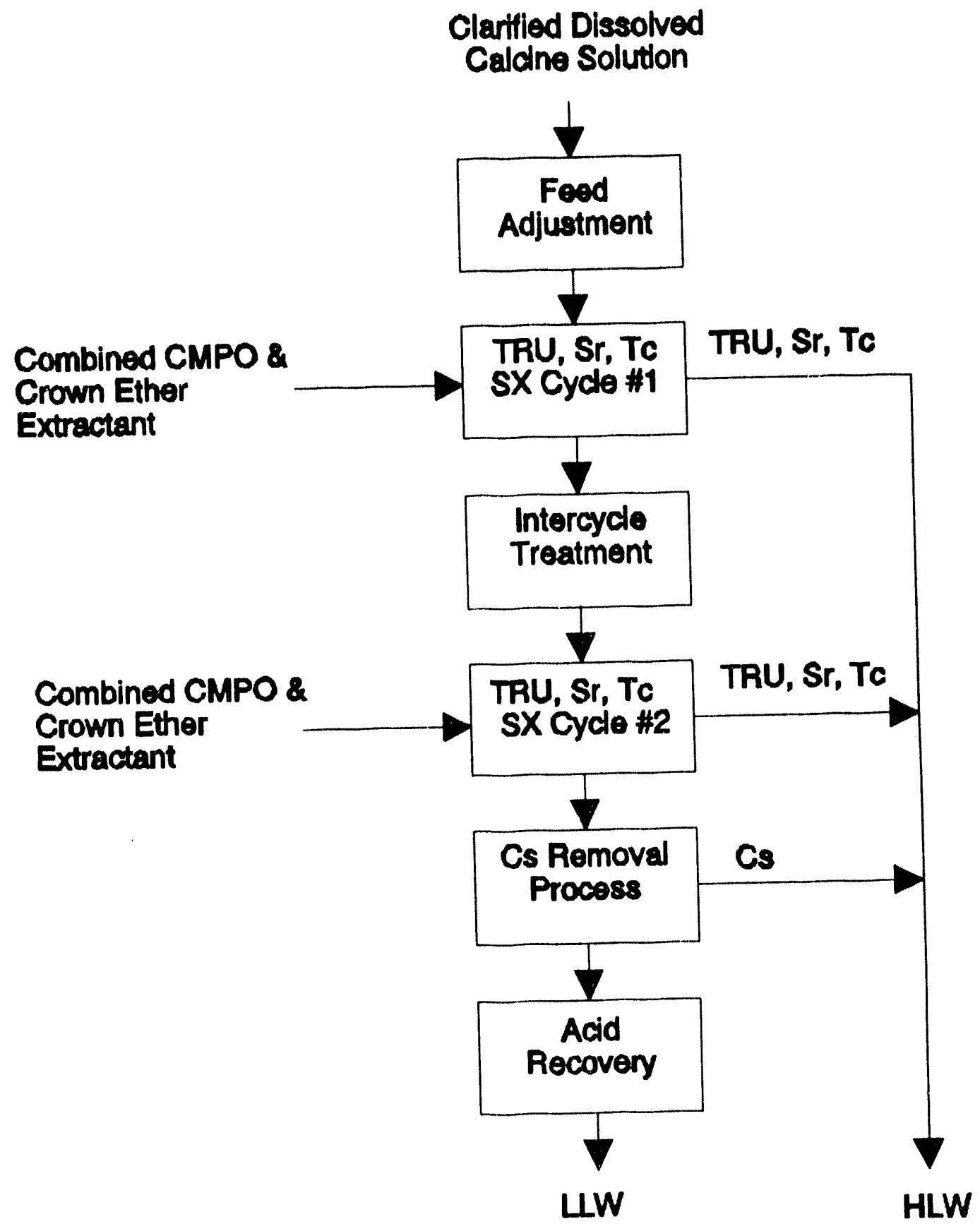

Figure 5-4. Simplified Radionuclide Removal Using Combined Solvent Extractants 
provide the needed removal of TRU elements, ${ }^{90} \mathrm{Sr}$, and ${ }^{90} \mathrm{TC}$. Consolidation of three extraction cycles into two presents a clear advantage in that only one solvent system is used. The ${ }^{137} \mathrm{Cs}$ removal alternatives indicated in Figure 5-3 also apply to the combined solvent approach of Scheme 3 .

\subsubsection{Scheme 4 (Figure 5-5)}

Figure 5-5 illustrates a potentially very attractive flowsheet approach which makes use of promising ${ }^{137} \mathrm{Cs}$-removal technology which has not yet been suitably demonstrated. This new technology includes the cobalt dicarbollide solvent extraction process and a crystalline silicotitanate ion exchange process. Under proper flowsheet conditions, both these ${ }^{137} \mathrm{Cs}$ removal processes should also remove some ${ }^{90} \mathrm{Sr}$ and can thus serve as one of the two cycles required for adequate ${ }^{90} \mathrm{Sr}$ removal. In the process scheme depicted in Figure 5-5 it is assumed that one cycle of solvent extraction using the combined CMPO-crown ether-TBP-NPH solvent would be used to accomplish required removal of TRU elements and ${ }^{99} \mathrm{TC}$ as well as residual ${ }^{90} \mathrm{Sr}$.

A potential disadvantage of the scheme illustrated in Figure 5-5 is that only one solvent extraction cycle is available for removal of ${ }^{99} \mathrm{Tc}$ and TRU elements. TRU element removal might be enhanced, however, if the crystalline silicotitanate exchanger sorbs TRU elements as well as ${ }^{137} \mathrm{Cs}$. In any event, both ${ }^{137} \mathrm{Cs}$ removal options will likely require feeds adjusted to $1 \mathrm{MHNO}_{3}$; raffinate from either cesium removal step will then have to be adjusted to an acidity suitable for operation with the combined process solvent.

\subsubsection{Scheme 5 (Figure 5-6)}

This conceptual scheme features water leaching of the calcine, prior to acid dissolution, to solubilize a large fraction of the ${ }^{137} \mathrm{Cs}$. Subsequently, ${ }^{137} \mathrm{Cs}$ is removed from the water leach. Such operations, if actually technically feasible, have the potential for decreasing radiation shielding required for other partitioning operations. In the scheme shown in Figure 5-6, the Cs-free raffinate is evaporated to reduce its volume and then introduced into the calcine dissolution step. This routing allows for recovery of ${ }^{90} \mathrm{Sr}$ or any radionuclides also present in the water leach. As in 


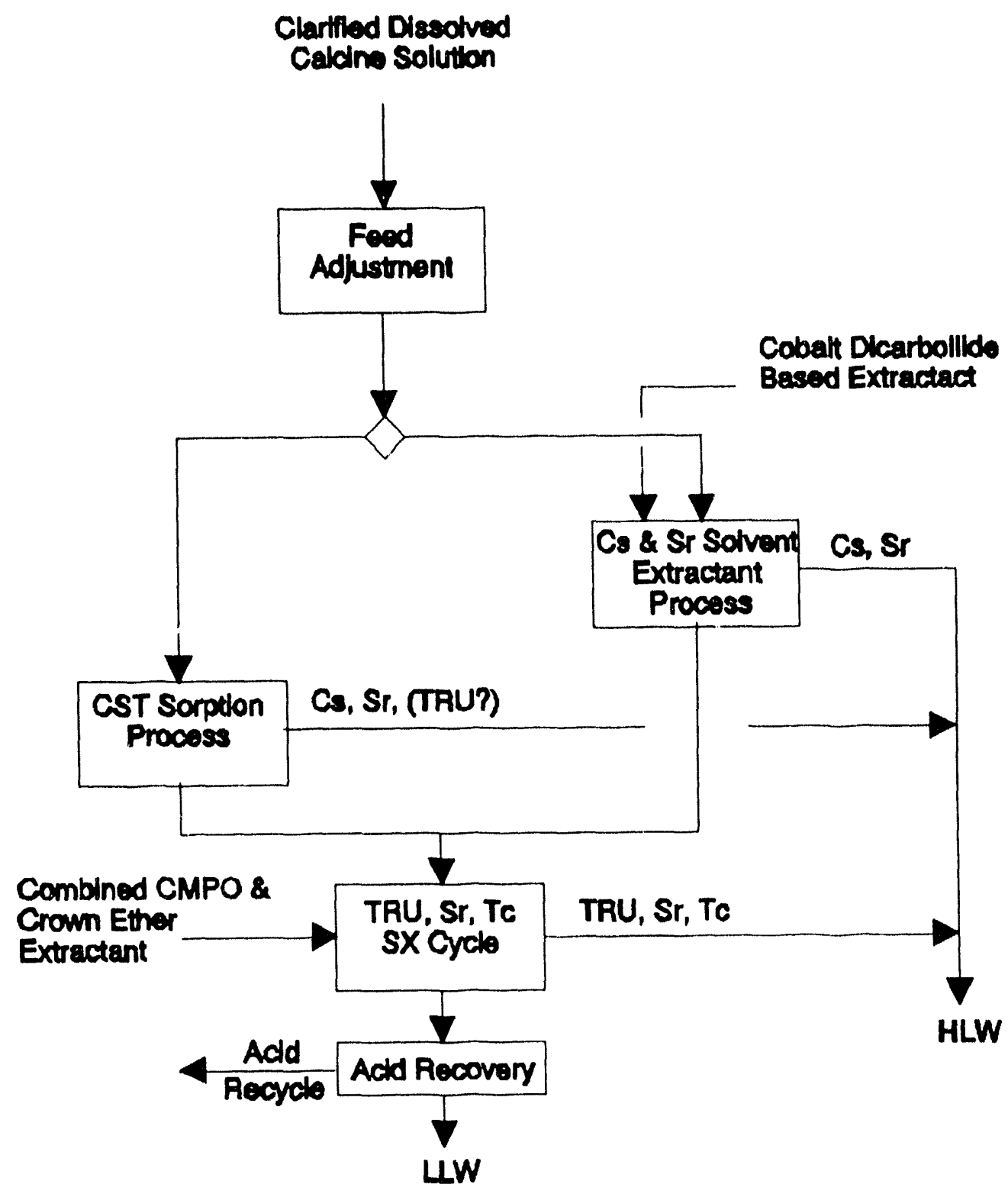

Figure 5-5. Application of Advanced ${ }^{137} \mathrm{Cs}$ Removal Technology 


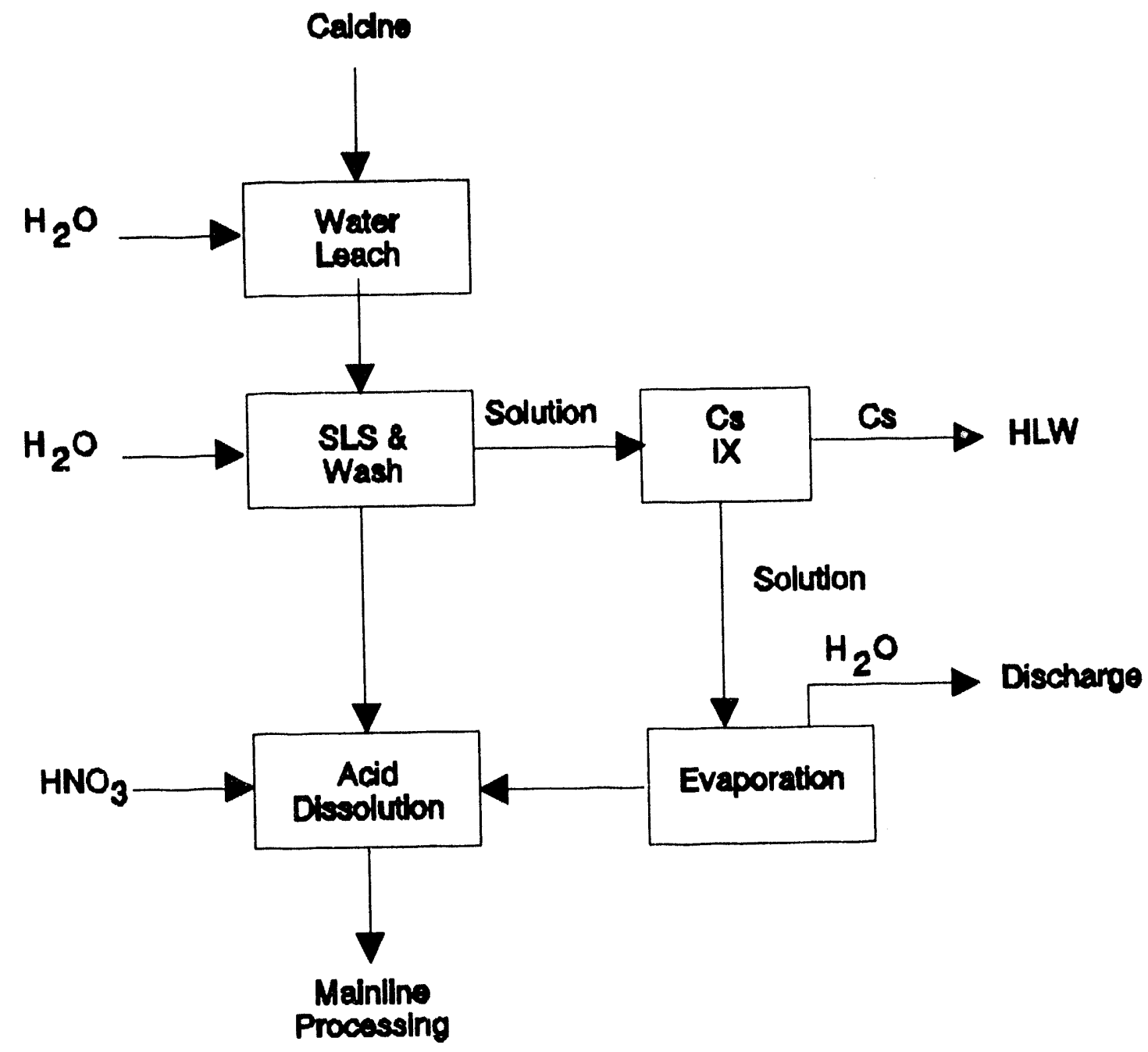

Figure 5-6. Potential Ion Exchange Removal of ${ }^{137} \mathrm{Cs}$ from Calcine Leach Solutions 
all leaching/dissolution steps, it is essential to achieve excellent separation of the water leachate from undissolved calcine. 


\subsection{LABORATORY TESTING RECOMMENDATIONS}

\subsection{INTRODUCTION}

The Panel, by virtue of their experience and knowledge, were asked to provide guidance and recommendations concerning bench-scale testing, by Westinghouse Idaho Nuclear Co. personnel, of highly-ranked separations technologies and processes (Sections 3.0, 4.0, and 5.0). This section summarizes the requested counsel and recommendations for tests with both simulated and actual ICPP calcine.

\subsection{LITERATURE AND OTHER RESOURCES}

There are, of course, a wealth of literature references to the separations processes and technology discussed in Section 3.0 of this report; only a few of the key references are cited in Section 7.0. The Panel recommends that the WINCO researchers not only locate and review the references 1 isted in Section 7.0 , but other reports and articles mentioned in these key references.

The Panel also recommends that WINCO management consider negotiating one to three week temporary assignments of some of their researchers to work with highly experienced separations specialists at the Argonne National Laboratory and, possibly, other DOE sites.

\subsection{CHARACTERIZATION OF PROCESS REAGENTS}

Historicllly, many nuclear separations process development studies were invalidateu or, at least, seriously compromised because researchers did not fully characterize chemical and physical properties of process reagents. To assure suitable data quality and that the desired radionuclide removal can be obtained, it is essential to determine reagent purity and relevant properties.

Particular attention needs to be paid to the purity and other properties of solvents and diluents to be used in cievelopment and testing of liquid-liquid extraction processes. For example, experience has shown that small concentrations of acidic impurities in neutral bifunctional 
organophosphorus extractants can seriously interfere with dilute $\mathrm{HNO}_{3}$ stripping of TRU elements. A standard methodology needs to be established for characterizing all diluent and extractant reagents.

At a minimum, solvent/diluent characterization regimes should include:

- Precision chromatographic (gas and other) analyses to quantitate various components.

- Standard distribution ratio measurements under both extraction and stripping conditions to establish behavior of ${ }^{241} \mathrm{Am},{ }^{90} \mathrm{Sr}$, and other key radionuclides.

- Quantitation of the isomeric content of crown ether extractants.

- If not already known, hydrolytic and radiolytic stability of candidate process extractants and diluents should be established.

Argonne National Laboratory solvent quality procedures and guidelines for acceptable TRUEX and SREX process extractants serve as a model of the kind of testing programs that should be put in place.

Ion exchange materials, both inorganic and or janic-based, al so need to be carefully characterized prior to use in tests with simulated and actual acidified ICPP calcine. Important properties to determine include:

- Particle Size Distribution

- Swelling/Shrinking Behavior

- Resistance to Attrition

- Chemical Stability in Both Alkaline and Acidic Solutions

- Uniformity from Batch to Batch

- Bulk Density

- Stability to Ionizing Radiation

- Pretreatment Needs, if any, Before Operations with Waste Solutions

- Capacity for elements of Interest

Standard methods for determining most of the listed parameters and properties are described in the literature. 


\subsection{SOLVENT EXTRACTION TEST PROCEDURES}

Much of the technology recommended (Section 4.0) for initial testing with acidifed ICPP calcine solution involves use of liquid-liquid extraction processes. These candidate solvent extraction processes need to be tested and adapted to ICPP calcine solutions using both simulated and actual acidified calcine solutions. On a bench-scale, the required testing should include, initially, batch contacts and, later, continuous counter-current runs with laboratory-scale contactors. The goal of such tests should be to obtain all the requisite information for design and operation of a pilot plant-scale solvent extraction system for determination of an optimized flowsheet. Appropriate references, e.g., Treybal (1963), Lowe, Baird, and Hanson, (1991), etc. should be consulted for guidance on the features of the experimental data needed to successfully develop a competent liquid-liquid extraction system.

Batch contacts should be performed to develop and test conditions for the scrubbing and stripping portions of the extraction flowsheet as well as the extraction portion. Typically, known volumes of organic and aqueous phases contained in screw-cap vials are mixed for a prescribed time at ambient temperature. Phases are intimately mixed either by use of magnetic stirrers or, alternatively, by means of a mechanical shaker. In some cases, phases contained in graduated centrifuge cones are mixed by means of overhead stirrers; jacketed cones are convenient for conducting batch extractions at elevated temperature. No matter the mixing method, phases are usually separated by centrifugation. Sampling of the phases must be done in a manner that prevents cross contamination between phases. Subsequently, samples of each phase are analyzed for components of interest by radiometric or other appropriate methods.

Important variables to be studied in extraction section studies include:

- Feed Acidity

- Feed Composition

- Organic Phase Composition

- Phase Ratio 
- Temperature

- Contact Time

Distribution ratios of all compounds of interest should be determined in each extraction contact experiment. Other parameters to observe in each contact are third (second organic) phase formation, disengaging properties, and raffinate stability toward precipitation of solids. In some cases, one portion of feed should be contacted with successive fresh portions of extractant to establish that required radionuclide decontamination factors ca: be achieved. In extraction contacts, some $\mathrm{HNO}_{3}$ will also likely transfer from the feed to the organic phase. Extraction of $\mathrm{HNO}_{3}$ can be prevented by preequilibrating the organic phase with simulated feed solution not containing any radionuclides. Knowledge of the aqueous phase acidity after contact is necessary for proper evaluation of the results.

Batch contact scoping experiments also should be performed to establish reagents and conditions for scrubbing $\mathrm{HNO}_{3}$ and metal contaminants, e.g., $\mathrm{Zr}$ (IV), $\mathrm{Fe}(\mathrm{III})$, etc. from the organic phase. Removal of $\mathrm{HNO}_{3}$ may be required, for example, to allow use of dilute $\mathrm{HNO}_{3}$ solutions to strip TRU elements. Scrub solutions containing small concentrations of fluoride ion or oxalate ion may be useful in removing $\mathrm{Zr}$ (IV), Fe(III), and other metal ions. Significant variables to be studied in scrub contacts are:

- Organic Feed Composition

- Scrub Composition

- Phase Ratio

- Contact Time

- Temperature

Distribution ratios of all components including $\mathrm{HNO}_{3}$ should be determined in each batch scrub contact.

To complete the batch-scale scoping investigation and development of candidate solvent extraction processes, it is necessary to establish conditions for stripping (back extraction) of radionuclides from scrubbed organic phases. Batch strip contacts can be performed to determine 
appropriate conditions, e.g., aqueous strip composition, organic-to-aqueous volume ratio, number of strip contacts, etc. for removal of radionuclides to a predetermined specification. In some cases, e.g., TRUEX process solvent and combined CMPO-crown ether solvent, the strip contact experiments can be designed to determine conditions for selective partitioning of individual radionuclides, $\mathrm{Am}$ (III), Pu(IV), ${ }^{99} \mathrm{Tc}$, or radionuclide fractions, e.g., TRU elements from ${ }^{90} \mathrm{Sr}$. A well-designed and executed series of batch contacts with both simulated and actual acidified ICPP calcine will provide the information needed to formulate a reference chemical flowsheet for testing on a continuous countercurrent basis in bench-scale contactors. Performance of the reference flowsheet and modifications thereof can be established in either conventional mixer-settlers or in advanced centrifugal contactors. (Results obtained in mixer-settlers can be used to design solvent extraction flowsheets for operation in pulse column contactors.) Initial countercurrent tests should be performed with simulated acid feeds to minimize the volume of actual acidified ICPP calcine. It is essential, however, that sufficient tests with actual waste solution be performed to verify operability of the reference flowsheet.

Vandegrift and coworkers at the Argonne National Laboratory have developed a computer code, Generic TRUEX Model, which simulates TRUEX process operation under various flowsheet conditions. This code is designed for use with desktop personal computers. Availability of the GTM code and its application to model extraction of TRU elements from acidified ICPP calcine will circumvent the need to conduct a large number of batch contacts and, possibly, many continuous countercurrent runs with simulated waste. Unfortunately, codes such as the GTM are not yet available for simulating the SREX, cobalt dicarbollide, or combined (e.g., TRUEX + crown ether) extraction processes.

\subsection{ION EXCHANGE/EXTRACTION CHROMATOGRAPHIC TEST PROCEDURES}

Development of an ion exchange or extraction chromatographic process usually begins with batch contacts and proceeds to fixed-bed column tests. In the batch contact tests, a known weight of sorbent is contacted with a known volume of solution for a predetermined time. Distribution ratios $\left(k_{d} s\right)$ for 
components of interest are calculated from radiometric measurements of radionuclides in the liquid before and after contact with the sorbent and are expressed in units of $\mathrm{ml} / \mathrm{gram}$. In some cases, a known weight of sorbent from previous loading-type batch contacts may be contacted with a known volume of candidate wash or eluent solutions. Variables of importance in batch contact tests include:

- Temperature

- Contact Time

- Solid/Liquid Ratio

- Sorbent Capacity

Data obtained in batch contacts will provide sufficient information for follow-on bench-scale column tests with both simulated and actual acidified ICPP calcine. Important variables to be studied in bench-scale column runs include:

- Feed Flow Rate

- Wash Flow Rate

- Eluent Flow Rate

- Bed Dimensions, Minimum Bed Depth

- Shape of Loading Breakthrough Curve

- Time to Loading Breakthrough

- Shape of Elution Curve

- Shape of Washing Curve

As in batch contact tests, appropriate radiometric and other analytical measurements should be made to determine behavior of components of interest. Various types of fixed-bed column operation, e.g., successive load-wash-elute; columns-in-series; parallel bed operation, etc, should be explored in bench-scale column tests. Appropriate manipulation of bench-scale column data, using well-established calculational procedures described in various references, will allow selection and design of pilot plant-scale and plant-scale systems for achieving required column performance. 


\subsection{PRECIPITATION/COPRECIPITATION PROCESS TEST PROCEDURES}

Bench-scale precipitation processes are typically performed at ambient temperature in small beakers (magnetically stirred) or in specially-fabricated graduated centrifuge cones. The latter greatly facilitate solid-liquid separation operations and measurement of the volume of the separated phases. Agitation of solid and liquid phases in centrifuge cones is usually accomplished with the aid of glass stirrers mounted in movable overhead motors. Jacketed contactors and circulating baths are typically used in studies of precipitation processes at elevated temperatures.

Parameters which should be addressed in bench-scale investigations of precipitation and co-precipitation studies include:

- Order of Mixing

- Forward Strike: Add Precipitant to Waste Solution

- Reverse Strike: Add Waste Solution to Precipitant

- Precipitant Concentration

- Carrier (if used) Concentration

- Rate of Addition of Precipitant or Waste Solution

- Digestion Time

- Temperature

- Reagent Mixing

- Digestion

- Agitation Conditions

The most important property to measure in each precipitation experiment is the completeness of precipitation of the candidate radionuclide (or radionuclides). Radior iric analys is of supernatant liquids produced in experiments in which an appropriate radioactive isotope is added to the waste solution will quickly provide the desired decontamination data. When precipitation conditions which provide necessary and/or desired decontamination factors have been established, important properties of the precipitated solids must be determined. Such properties include:

- Type of Precipitate

- Crystalline 
- Gelatinous

- Other

- Particle Size as Function of Digestion Time

- Particle Density

- Redissolution Characteristics

- Volume and Mass

- Ease of Solid-Liquid Separation

- Centrifugation

- Filtration

- Compatibility with Final Waste Form

- Glass

- Ceramic 


\subsection{REFERENCES}

1. Barney, G. S. and R. G. Cowan, 1992, Separation of Actinide Ions from Radioactive Waste Solutions using Extraction Chromatography, WHC-SA-1520PP, Westinghouse Hanford Company, Richland, Washington

2. Berreth, J. R., 1988, Inventories and Properties of ICPP Calcined High-Level Waste, WINC0-1050, Westinghouse Idaho Nuclear Co., Idaho Falls, Idaho

3. Berreth, J. R. and B. R. Dickey, 1982, Proc. Amer. Nucl. pp. 449-454, Apri1

4. Berreth, J. R. and D. A Knecht, 1984, "Defense High Level Waste Management at the Idaho Chemical Processing Plant," Proceedings of Institute of Nuclear Materials Management, Vol XIII, Columbus, Ohio

5. Brown, N. E., 1993, "Private Communication", Sandia National Laboratories, Albuquerque, New Mexico

6. Burney, G. A. and J. A. Porter, 1967, J. Inorg. Nucl. Chem. Lett., $\underline{3}, 79$.

7. Butler, P. C. and D. R. Tramme11, 1977, Calcine Dissolution Study, Technical Division Quarterly Progress Report July 1-September 30, 1977, ICP-432, Idaho Falls, Idaho

8. Butler, P. C. and D. R. Trammel1, 1978, Calcine Dissolution Study, Technical Division Quarterly Progress Report, October 1 December 31,1977 , ICP-1141, Idaho Fal1s, Idaho

9. J. P. Bibler and R. M. Wallace, 1987, Preparation and Properties of a Cesium- Specific Resorcinol-Formaldehyde Ion Exchange Resin, DPST-87-647, Savannah River Laboratory, E. I. du Pont de Nemours, Co., Aiken, South Carolina

10. Dukas, S. J., et al., 1986, Electrolytic Dissolution Experience at the Idaho Chemical Processing Plant, WINCO-M-10074, Westinghouse Idaho Nuclear Company, Idaho Falls, Idaho

11. Henry, R. N., et al., 1973, Processing of Zirconium and Aluminum Fuels During 1972, ICP-1024, Idaho Falls, Idaho

12. Hogg, G. W., et a7., 1973, Development of Processes and Equipment for Recovering Uranium from Rover-Fuels-Burner Ash, ICP-1016, Idaho Falls, Idaho

13. Horwitz, E. P., M. L. Dietz, and D. E. Fisher, 1990, Solvent Extr. Ion Exch., 8,199

14. Horwitz, E. P., R. Chiarizia, and M. L. Dietz, 1992, Solvent Extr. Ion Exch., 10, 313 
15. Koiarik, Z., 1991, Separation of Actinides and Lonq-Lived Fission Products from High-Level Radioactive Wastes (A Review), KFK-4945, Kernforschungszentrumm, Karlsruhe, Germany

16. S. D. Reilly, C. F. V. Mason, and P. H. Smith, 1992, Cobalt (III) Dicarbollide, A Potential ${ }^{137} \mathrm{Cs}$ and ${ }^{90}$ Sr Waste Extraction Reagent, LA-11695, Los Alamos National Laboratory, Los Alamos, New Mexico

17. Lowe, T. C., Baird, M. H. I., and C. Hanson, 1991, Handbook of Solvent Extraction, Krieger Pub. Co., Malabar, Florida

18. Madic, C., C. Kerterz, P. Sontag, and G. Koehly, 1980, Sep. Sci. \& Tech., 15,745

19. McLain, M. E. and D. W. Rhodes, 1958, Leaching of Fission Products from Calcined Processed Waste, IDO-1440, Phillips Petroleum Co., Idaho Falls, Idaho

20. NRC, 1988, "Licensing Requirements for Land Disposal of Radioactive Waste, " Code of Federal Regulations, Nuclear Regulatory Commission, Washington, D.C.

21. Paige, B. E., 1966, Leaching of Alumina Calcine Produced in the Idaho Waste Calcining Facility, IN-1011, Idaho Falls, Idaho

22. Rais, J., P. Selucky, and M. Kyrs, 1976, J. Inorg. Nucl. Chem., 38, 1376

23. Schulz, W. W. and L. A. Bray, 1987, Sep. Sci. \& Tech., 22, 191

24. Staples, B. A., B. E. Paige, and D. W. Rhodes, 1982, Nucl. Tech., 56, 301

25. Treybal, R. E., 1963, Liquid Extraction, 2nd Ed., McGraw Hill Book Co., New York, New York

26. 1972, Plans for the Management of ERDA-Generated Radioactive Wastes, WASH-1202, Division of Waste Management and Transportation, Energy Research and Development Administration, Washington, D. C., p. 35.

27. 1990, CURE: Clean Use of Reactor Energy, WHC-EP-0268, Westinghouse Hanford Co., Richland, Washington

28. 1993, Alternative Pretreatment Technologies for Removal of Transuranium Elements from Selected Hanford Site Wastes, WHC-EP-0577, Westinghouse Hanford Co., Richland, Washington

29. Wheeler, B. R., et a1., 1966, Uranium Recovery from Aluminum Alloyed Fuel-ICPP Run No. 2, ID0-14669, Idaho Falls, Idaho

30. Wilding, M. W. and D. W. Rhodes, 1969, Leachability of Zirconia Calcine Produced in the Idaho Waste Calcining Facility, IN-1298, Idaho Falls, Idaho

31. Yamada, W. I., L. L. Martella, and J. D. Navratil, 1982, J. Less Common $\underline{\text { Metals, }}, \underline{86}, 211$ 
APPENDIX A. SELECTED DATA CONCERNING SOURCE, COMPOSITION AND PROPERTIES OF ICPP CALCINE

\section{TABLES}

Table A-1. Inventory of Calcine in Storage at the ICPP as of December 31, 1986 (Table 2-1 in WINCO-1050)

Table A-2. Physical properties of Calcined ICPP High-Level Waste (Table 3-1 in WINCO-1050)

Table A-3. Representative Chemical Composition of ICPP Calcined Waste (Table 4-2 in WINCO 1050)

Table A-4. Approximate Calcine Composition by Bin Set (Table 4-4 in WINCO-1050)

Table A-5. Chemical Properties of Calcined waste (Table 4-7 in WINCO-1050)

Table A-6. Radionuclide Inventory of Calcined Waste as of December 31, 1986 (Table 5-2 in WINCO-1050)

Table A-7. Radionuclide Inventory by Bin Set as of December 31, 1986 (Table 5-3 in WINCO-1050)

\section{FIGURES}

Figure A-1. Configuration of Calcine Storage Facilities at the ICPP (Figure 1-2 in WINCO-1050)

Figure A-2. Calcine Stratification in the Second Bin Set (Figure 2-1 in WINCO-1050)

Figure A-3. Calcine Stratification in the Third Bin Set (Figure 2-2 in WINCO-1050) 


\section{APPENDIX B. BIOGRAPHICAL INFORMATION FOR SEPARATIONS EXPERTS PANEL}

\section{CLARK D. CARLSON}

Dr. Carlson is a Research Scientist in the Chemical Technology Department of the Pacific Northwest Laboratory at the U.S. Department of Energy's Hanford Site. For the past year, he has been working on research and development activities at the Hanford Site, including separations process chemistry for the removal of actinides and fission product elements from fuel reprocessing waste streams. Dr. Carlson has also worked at the U.S. Environmental Protection Agency Region 10 Laboratory in the area of novel remediation technology at Superfund sites. He holds a $\mathrm{Ph}$. D. in inorganic chemistry from Iowa State University.

\section{LARRY BURCHFIELD}

Dr. Burchfield is recognized internationally as an expert in lanthanide and antinide chemistry, alpha spectroscopy, analytical radiochemical separations, and radiochemical methods development. He has seven years experience in the DOE complex and in 1991 he entered the private sector by cofounding Oak Ridge Analytical Services, Inc., located in Oak Ridge, Tn. Oak Ridge Analytical Services specializes in bioassay and environmental radiochemistry with capabilities of performing analysis on over eighty radionuclides from not only the lanthanide and actanide series but the alkaline earths, transition metals, noble gases, and halides as well.

Dr. Burchfield has also worked as a consultant throughout the DOE complex and with several international agencies such as the International Atomic Energy Agency. He has authored eight papers in the field of environmental radiochemistry and has made significant contributions in methods development for the difficult-to-measure radionuclides, such as ${ }^{94} \mathrm{Nb},{ }^{99} \mathrm{Tc}$, and ${ }^{129} \mathrm{I}$. He holds a copyright on an alpha spectroscopy software counting package currently being marketed by Canberra Instruments.

Dr. Burchfield received his Ph.D. in radiochemistry in 1982 from the University of Arkansas.

ARLIN L. OLSON

$\mathrm{Mr}$. Olson is an Advisory Engineer with Westinghouse Idaho Nuclear Co., Inc., at the Idaho Chemical Processing Plant. He has twenty years of commercial and Department of Energy Complex experience in recovery of uranium and plutonium from spent nuclear reactor fuels, separation of radionuclides, and radioactive waste management. This includes design, pilot scale development, and operation of nuclear related processing facilities. Most of this time has been spent at the Idaho Chemical Processing Plant, but three years were spent at the Barnwell Nuclear Fuel Plant as Supervisor of Process Engineering and two years at the Oak Ridge National Laboratory as a reprocessing consultant. He has authored or co-authored over 20 publications in the areas of spent nuclear fuel reprocessing development and operation, waste management, and plutonium processing and has one patent. He has $B$. S. and $M$. S. degrees in Chemical Engineering from the University of Idaho, Moscow, Idaho. 
WALLACE W. (WALLY) SCHULZ

Wally Schulz is an internationally recognized authority on nuclear separations process chemistry and technology. He spent his early professional career (1950-1988) at the U. S. Department of Energy Hanford Site where he was employed by various contractor companies. While at Hanford, Wally devised and developed many important processes for separation, recovery, and purification of fissile materials from irradiated fuels and of radionuclides from solid and liquid fuel reprocessing wastes; several of these processes were used very successfully on a plant-scale. Since retiring from Westinghouse Hanford Company in August, 1988, Wally has provided independent consulting services on nuclear separations to government agencies, government contractors to the DOE, and to private industry.

Wally has been awarded many honors and much recognition by his professional colleagues. He is a member of several professional societies and is especially active in the American Chemical Society where he has served as Chairman of the Industrial Chemistry and Engineering Division and also Chairman of the Separation Science and Technology Subdivision.

Wally has been awarded 21 patents and has published well over 100 journal papers; he has also written or edited 10 books.

\section{JOHN L. SWANSON}

Mr. Swanson is a Staff Scientist in the Chemical Process Systems Section, Chemical Development Department of Battelle's Pacific Northwest Laboratory at the U.S. Department of Energy Hanford Site. He has over 40 years of experience in research and development activities at the Hanford site, primarily in the areas of process chemistry and development of separations processes. In recent years, the emphasis of his studies has been on processes for removal of actinides and fission product elements from fuel reprocessing plant waste streams. John holds a B. S. degree in chemistry from Reed College, Portland, Oregon.

MAJOR C. THOMPSON

Major is an Advisory Scientist at the DOE Savannah River Site and is employed by the Westinghouse Savannah River Co. in Aiken, South Carolina. Major came to the Savannah River site after receiving his $\mathrm{Ph}$. D. from Ohio State University. Major has worked in a wide variety of areas. His principal areas of expertise are actinide chemistry and separations

chemistry/technology. He has studied separations using pyrochemistry, solvent extraction, ion exchange, and precipitation techniques principally for support of plant operations. He developed and demonstrated the modified PUREX process presently used at the Savannah River Site to recover enriched uranium from irradiated fuels. He also developed a solvent extraction flowsheet used at the Savannah River Site to recover about $10 \mathrm{~kg}$ of americium and $4 \mathrm{~kg}$ of curium from Purex waste. Major has also been responsible for other improvements to the PUREX process operated at the Savannah River site, especially in partitioning uranium from plutonium with reductants which do not increase the 
amount of waste generated. More recently, he has studied the solubility of actinides in waste solutions and removal of actinides and fission product elements from waste solutions.

He holds a Ph.D in inorganic chemistry from Ohio State University. 

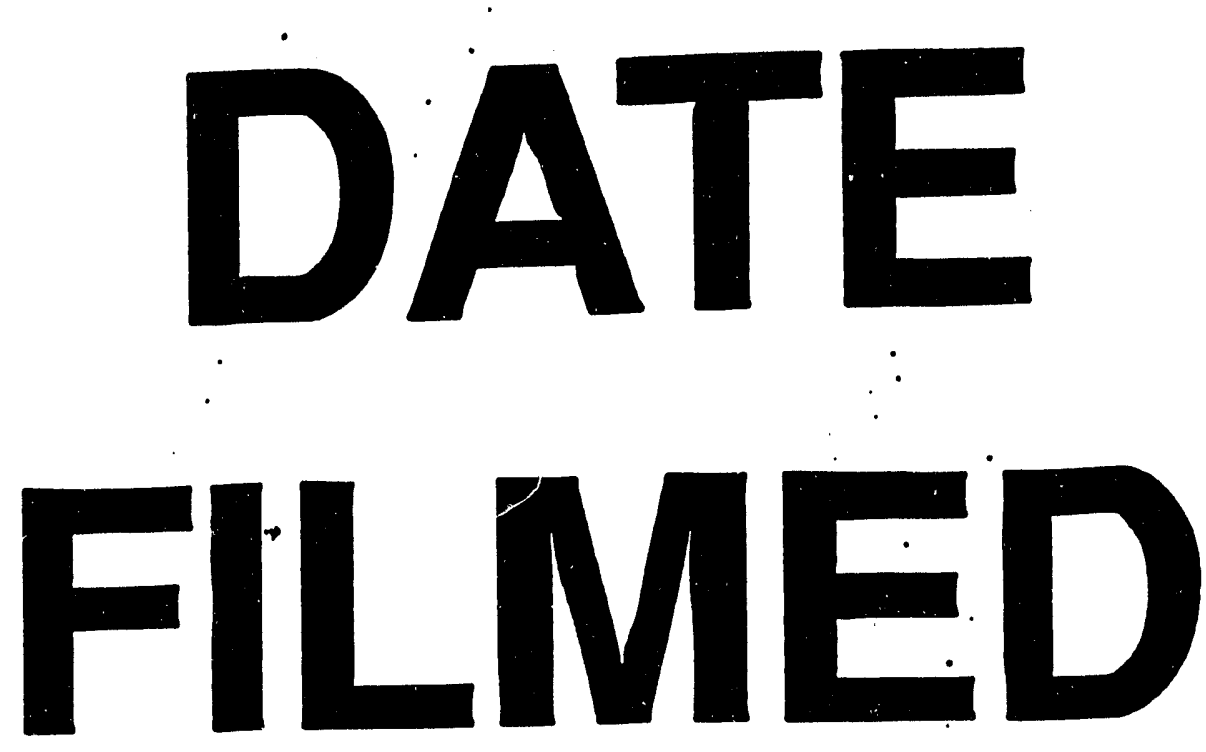

$4 / 25 / 94$
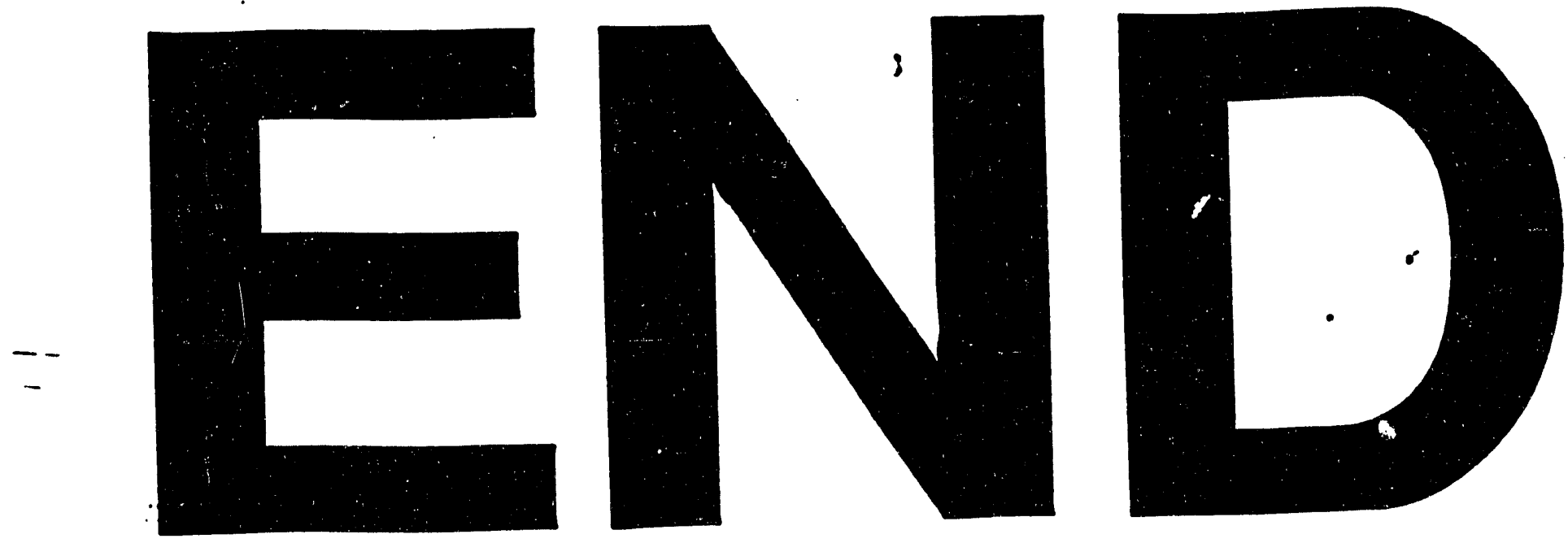
